Florida International University FIU Digital Commons

$11-12-2015$

\title{
Impacts of Climate, Land Cover and Hydrologic Changes on Stormwater Runoff in Central Florida
}

Mohammad S. Islam

Florida International University, misla024@fiu.edu

DOI: $10.25148 /$ etd.FIDC000189

Follow this and additional works at: https:// digitalcommons.fiu.edu/etd

Part of the Civil Engineering Commons

\section{Recommended Citation}

Islam, Mohammad S., "Impacts of Climate, Land Cover and Hydrologic Changes on Stormwater Runoff in Central Florida" (2015). FIU Electronic Theses and Dissertations. 2290.

https://digitalcommons.fiu.edu/etd/2290 


\title{
FLORIDA INTERNATIONAL UNIVERSITY
}

Miami, Florida

\section{IMPACTS OF CLIMATE, LAND COVER AND HYDROLOGIC CHANGES ON STORMWATER RUNOFF IN CENTRAL FLORIDA}

\author{
A thesis submitted in partial fulfillment of \\ the requirements for the degree of \\ MASTER OF SCIENCE \\ in \\ CIVIL ENGINEERING \\ by
}

Mohammad Saiful Islam 
To: Interim Dean Ranu Jung

College of Engineering and Computing

This thesis, written by Mohammad Saiful Islam and entitled Impacts of Climate, Land Cover and Hydrologic Changes on Stormwater Runoff in Central Florida, having been approved in respect to style and intellectual content, is referred to you for judgment.

We have read this thesis and recommend that it be approved.
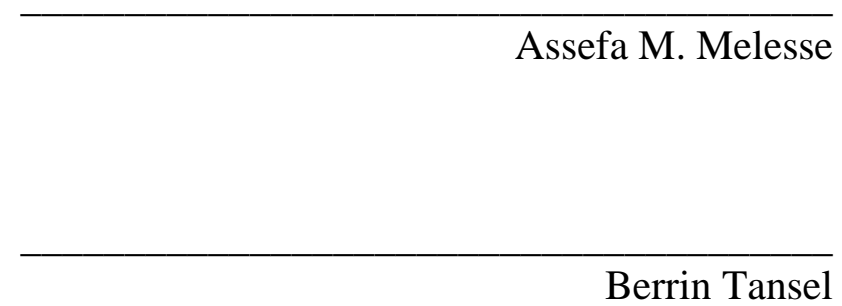

Berrin Tansel

Omar I. Abdul-Aziz, Major Professor

Date of Defense: November 12, 2015

The thesis of Mohammad Saiful Islam is approved.

Interim Dean Ranu Jung
College of Engineering and Computing

Florida International University, 2015 


\section{ACKNOWLEDGMENTS}

I would like to express my sincere gratitude to my advisor Dr. Omar I. Abdul-Aziz for his continuous mentoring, advice and encouragement throughout my graduate studies at FIU. I would also like to thank my thesis committee members, Dr. Assefa M. Melesse and Dr. Berrin Tansel, for their time, assistance and valuable suggestions that helped me greatly in completing this research. I am grateful to my entire family, especially my wife, Tasnuva Mahjabin, for her immense support and encouragement during my hard times.

The research was financially supported by the State of Florida Office of Insurance Regulations through the "Florida Public Hurricane Loss Model Enhancements" project. 


\title{
ABSTRACT OF THE THESIS \\ IMPACTS OF CLIMATE, LAND COVER AND HYDROLOGIC CHANGES ON STORMWATER RUNOFF IN CENTRAL FLORIFA
}

\author{
by \\ Mohammad Saiful Islam
}

Florida International University, 2015

Miami, Florida

Professor Omar I. Abdul-Aziz, Major Professor

Changes in climate and land use/cover can cause great impacts on the hydrologic processes, especially on stormwater runoff generation. Considering the Shingle Creek Basin in Central Florida as an example of complex inland urban-natural basins, we quantified reference sensitivities of stormwater runoff to plausible scenarios of climatic, land use/cover and hydrologic changes by developing a dynamic rainfall-runoff model with the EPA Storm Water Management Model (SWMM 5.1). Potential storm runoff in the coupled urban-natural basin exhibited high and notably different seasonal sensitivities to rainfall. The total basin runoff was highly sensitive to the basin imperviousness, while showing moderate to low sensitivities to the evapotranspiration, slope and roughness. The changes in runoff under simultaneous hydro-climatic and climate-land cover perturbations were notably different than the summations of their individual contributions. The study findings can be useful in managing stormwater runoff in the Shingle Creek and similar complex urban-natural basins around the world. 


\section{TABLE OF CONTENTS}

CHAPTER $\quad$ PAGE

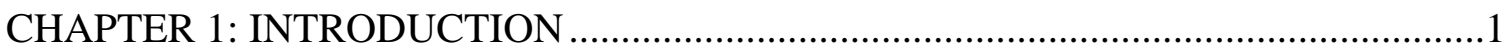

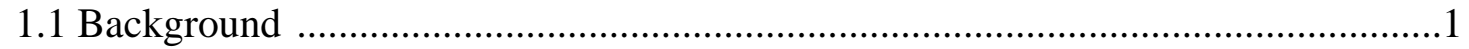

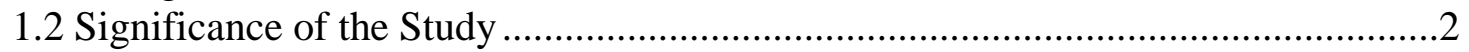

1.3 Objectives of the Study.......................................................................................... 2

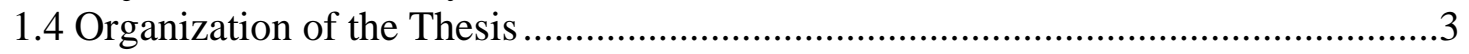

CHAPTER 2: LITERATURE REVIEW .................................................................

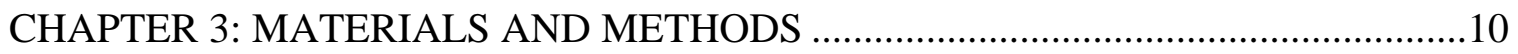

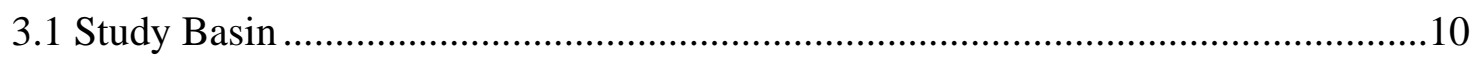

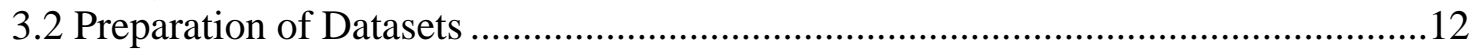

3.2.1 Weather Data ........................................................................................12

3.2.2 Groundwater Data .................................................................................

3.2.3 Soil Type and Imperviousness Data ................................................................16

3.2.4 Stream Flow and Bathymetric Data .............................................................19

3.2.5 Digital Elevation Model ................................................................................20

3.3 Model Development.............................................................................................21

3.3.1 Storm Water Management Model (EPA SWMM 5.1) .....................................21

3.3.2 Model Setup ...................................................................................................23

3.3.2.1 Subcatchment Discretization and Stream Network Delineation...............23

3.3.2.2 Subcatchment and Stream Network Parametrization ..............................25

3.3.3 Model Calibration and Validation ..................................................................26

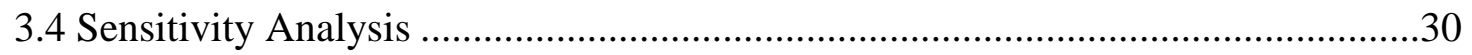

3.4.1 Sensitivity Scenarios and Selected Parameters ...................................................31

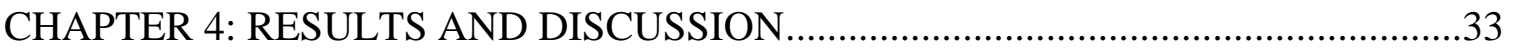

4.1 Model Evaluation............................................................................................33

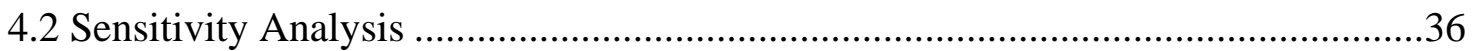

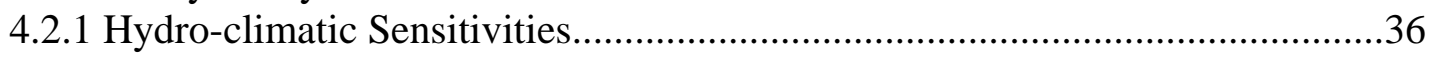

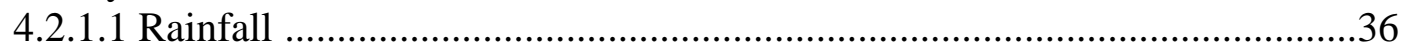

4.2.1.2 Evapotranspiration ....................................................................................39

4.2.2 Land Cover and Hydrologic Sensitivities .........................................................41

4.2.2.1 Imperviousness .......................................................................................

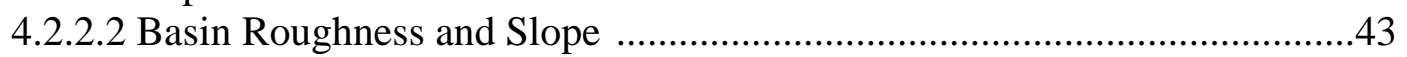

4.2.3 Combined Hydro-climatic and Land Cover Sensitivities .....................................44

4.2.3.1 Combined Rainfall and Evapotranspiration Sensitivities ................................45

4.2.3.2 Combined Rainfall and Imperviousness Sensitivities......................................46

4.2.3.3 Combined Imperviousness and Evapotranspiration Sensitivities ....................47

4.3 Comparison with Previous Studies ..................................................................... 48 
CHAPTER 5: CONCLUSIONS AND RECOMMENDATIONS ...................................50

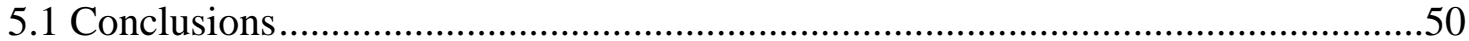

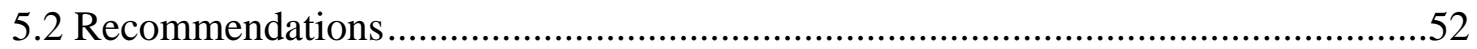

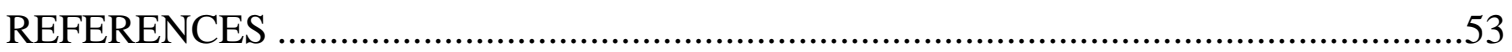

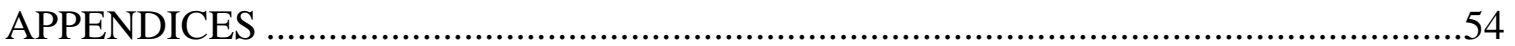




\section{LIST OF FIGURES}

FIGURE

PAGE

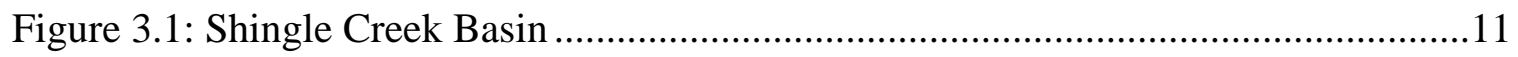

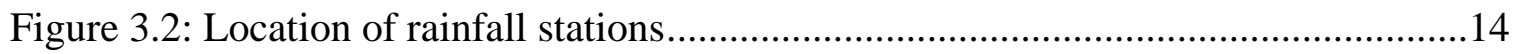

Figure 3.3: Groundwater Observation wells used for the model...................................16

Figure 3.4: Distribution of soil types in Shingle Creek. ............................................17

Figure 3.5: NLCD 2011 Percent imperviousness data...............................................18

Figure 3.6: Observed daily stream discharge at calibration point for 2012 and 2013 .......19

Figure 3.7: Shingle Creek digital elevation model (DEM) .......................................20

Figure 3.8: Representation of SWMM runoff algorithm (Giron, 2005) ..........................22

Figure 3.9: Delineated streams, nodes and subcatchments for the model development ...24

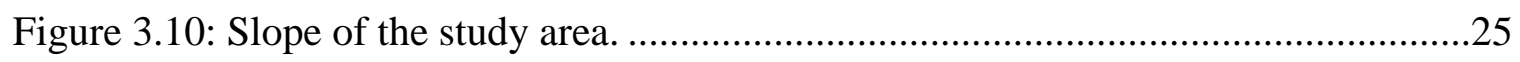

Figure 3.11: Calibration point near the outlet of the basin .........................................28

Figure 4.1: Observed vs Simulated mean daily stream discharge for 2012.....................34

Figure 4.2: Observed vs Simulated mean monthly stream discharge for 2012................34

Figure 4.3: Observed vs Simulated mean daily stream discharge for 2013......................35

Figure 4.4: Observed vs Simulated mean monthly stream discharge for 2013................35

Figure 4.5: Monthly average rainfall of 2012 in Shingle Creek Basin............................38

Figure 4.6: Changes in runoff for different changes in rainfall ...................................38

Figure 4.7: Monthly average evapotranspiration (2004-2014) in Shingle Creek Basin ...40

Figure 4.8: Changes in runoff for different changes in evapotranspiration ....................40

Figure 4.9: Changes in runoff for different changes in Imperviousness.........................42

Figure 4.10: Changes in runoff for $20 \%$ increase in roughness and slope ......................44 
Figure 4.11: Changes in runoff for combined increases in rainfall and ET.....................45

Figure 4.12: Changes in runoff for combined increases in rainfall and imperviousness...46

Figure 4.13: Changes in runoff for combined increases in imperviousness and ET ........47 


\section{CHAPTER 1}

\section{INTRODUCTION}

\subsection{Background}

Increasing concentration of greenhouse gases has caused atmospheric radiative imbalance and thus altered temperature and precipitation patterns (Houghton et al., 2001). Changes in these climatological variables have great implications over the hydrologic cycle especially on stormwater runoff generation. For example, increased amount of precipitation may lead to increase in runoff, and vice versa. In addition, changes in land covers due to urbanization have profound impacts on runoff. Therefore, it is imperative to have a clear understanding about the complex inter-relationship between stormwater runoff and different hydro-climatic and land use/land cover variables for proper watershed management.

Hydrologic and hydraulic modeling has been a useful tool to quantify stormwater for different climate and land use scenarios. It enables decision makers to envision probable situations and help them to plan required mitigation and adaptation techniques. Many studies have focused on quantifying climate change effects of runoff generation (Chang and Jung 2010; Ghosh and Dutta, 2012; Vastila et al., 2010). However, further research is needed to understand the dynamics involved in urban runoff generation. 


\subsection{Significance of the Study}

Hydrological models have been used worldwide to assess potential hydrologic impacts on water resources due to probable changes in land use (Matheussen et al., 2000) and climate variables (Nijssen et al., 2001). This research focused on computing monthly and annual reference stormwater sensitivities for Shingle Creek Basin in Central Florida by developing a dynamic rainfall-runoff Storm Water Management Model (EPA SWMM 5.1). Two major hydro-climatic variables (i.e., rainfall and evapotranspiration) and three land cover and hydrologic variables (i.e., imperviousness, basin slope and roughness) were considered for the study. The developed model incorporated all the important hydrologic processes underlying runoff generation, such as rainfall, evapotranspiration, groundwater in addition to land cover characteristics. The computed sensitivities can provide useful insights for effective stormwater management for the study area as well as similar urban-natural watersheds around the world.

\subsection{Objectives of the Study}

The primary focus of this research was to compute basin scale monthly and annual stormwater sensitivities to major hydro-climatic, hydrologic and land cover variables for Shingle Creek Basin in Central Florida.

The research was carried out by evaluating the following three specific objectives.

- To develop a dynamic rainfall-runoff model for Shingle Creek Basin in Central Florida using the EPA Storm Water Management Model (SWMM 5.1). 
- To quantify monthly as well as annual stormwater sensitivities to major hydroclimatic, land cover and hydrologic variables.

- To evaluate combined hydro-climatic and land cover sensitivities of potential stormwater for the study basin.

\subsection{Organization of the Thesis}

The thesis consists of five distinct chapters. The current chapter discusses background and significance of the research, along with the objectives and organization of the thesis. Chapter 2 reviews detailed literature related to the hydrological modeling efforts on runoff processes. Chapter 3 presents the study area, preparation of datasets and the detailed methodology involved in this research. Chapter 4 includes the research findings as well as discusses the plausible explanations. Chapter 5 summarizes the study outcomes and provides recommendations for future research. 


\section{CHAPTER 2}

\section{LITERATURE REVIEW}

Hydrological models have been used worldwide to assess the potential hydrologic impacts on water resources due to probable changes in both land use and climate variables. Xu et al. (2005) reviewed different methodologies used by many studies and reported achievements and future challenges involved in the simulation of hydrological consequences due to changes in climate variables. Generally, there are three steps involved in assessing future climate impacts on water resources (Xu, 1999): (1) using general circulation model (GCMs) to predict future global climate scenarios under the rising effects of green-house gases, (2) using regional climate models (RCMs) and different statistical methods to downscale GCM outputs to the model scales for better predictions, and (3) development of hydrological models for simulating the hydrological consequences at different scales. Much improvement has been achieved in each of these three steps in recent times. For example, vertical water distributions in GCMs have been improved by replacing simple bucket models with more physically-based SVAT models (Dolman, 2001). Also, different statistical downscaling methods have been developed (Hellstrôm and Chen, 2003; Wetterhall et al., 2005 a, b; Wilby et al., 2000) and more physically based RCMs are implemented for better atmospheric predictions (Hay et al. 2002; Samuelsson et al., 2003). A significant amount of improvement is also seen in model development by incorporating more realistic physical processes (Engeland et al., 2001; Graham, 2004; Ma et al., 2000). However, each of these steps involves large undercities (Xu et al., 2005). 
An alternate approach named as "Hypothesized Scenarios" is also widely used by the hydrologist as an input to the catchment-scale hydrological models to quantify climate change impacts on water resources. As stated in $\mathrm{Xu}$ et al. (2005), the hypothesized method consists of the following procedures (Loaiciga et al., 1996; Xu, 1999):

(1) In the hydrologic model, estimate the parameter values for a study basin using current climatic inputs.

(2) Alter the historic climate time series based on some climate change scenarios.

(3) Simulate hydrological characteristics for the study basin using the altered climatic inputs.

(4) Compare the simulations of current and future hydrological characteristics of the study basin.

Abdul-Aziz and Al-Amin (2014) estimated climate and land use sensitivities of stormwater quantity and quality for Miami River basin by developing a rainfall-runoff model using SWMM. The study used hypothesized scenarios (by changing parameters $5 \%, 10 \%, 15 \%$ and $20 \%$ ) to quantify both hydro-climatic and land use/cover effects on runoff quantity and quality for the study area. The study estimated higher runoff sensitivities to rainfall and moderate sensitivities to land use/cover and hydrologic parameters. Notable seasonal sensitivities were also observed to rainfall as early dry winter and late wetter summer months exhibited stronger responses to runoff generation. Subbasin parameters such as basin roughness and imperviousness showed relatively 
higher influences on runoff than the basin's slope. Also land use changes showed relatively little effects on runoff generation. The study also estimated combined effects of the hydro-climatic and land use/cover parameters on runoff generation. Different results were observed for changing multiple scenarios at a time than the summations of their individual sensitivities.

$\mathrm{Xu}$ (2000) investigated climate change impacts on hydrological responses in Central Sweden by incorporating fifteen hypothetical scenarios (e.g., combination of $\Delta \mathrm{T}=$ $+1,+2$, and $+4{ }^{\circ} \mathrm{C}$ and $\Delta \mathrm{P}=0, \pm 10 \%, \pm 20 \%$ ) in a conceptual monthly water balance model. The study estimated the hydro-climatic effects for twenty five catchments (area ranging from $6 \mathrm{~km}^{2}$ to $1293 \mathrm{~km}^{2}$ ). It showed significant decrease in winter snow accumulation for all the climate scenarios. Winter runoff increased significantly for most of the cases whereas for spring and summer seasons, it decreased. Annual evapotranspiration showed relatively small changes compared to annual runoff and snow for these hypothesized scenarios.

Jiang et al. (2007) compared hydrological responses in the Dongjiang Basin, South China for fifteen perturbed climate change scenarios using six monthly water balance models. The study first evaluated the capability of these models in simulating the present scenario and then compared the impacts for hypothetical climate scenarios. Larger differences among the model simulated results were found for the hypothetical scenarios whereas smaller differences were observed for the present climate scenario. Similar studies have been carried out around the world using hypothesized scenarios to quantify hydrologic responses to climate change (Arnell and Reynard, 1996; Boorman 
and Sefton, 1997; Graham and Jacob, 2000; Leavesley, 1994; Nemec and Schaake, 1982).

Many studies have focused on quantifying the changes in stormwater runoff quantity and quality due to changes in relevant drivers and sources. Mathematical models (i.e., mechanistic and empirical) play an important role in identifying these changes by integrating different components of the stormwater processes. Bhaduri et al. (2000) assessed long term impacts of land use changes on average annual runoff and NPS (NonPoint Source) pollution in Little Eagle Creek (LEC) watershed near Indianapolis, USA. The study incorporated historical land use scenarios (1973, 1984 and 1991) in addition to long term climate and soil data, in long-term hydrologic impact assessment (L-THIA) model. The study estimated $80 \%$ increase in annual average runoff and more than 50\% increase in annual average pollutant loads (lead, copper, zinc) due to a $18 \%$ increase in urban areas for the given time period. A decrease of 15\% in nutrient loads (nitrogen and phosphorus) was also observed due to conversion of agricultural lands to urban areas in the study.

Lee and Heaney (2003) evaluated effects of urban imperviousness on storm water system for an apartment area in Miami. The study revealed dominant contribution from the directly connected impervious area (DCIA) on total runoff volume. The study also estimated differences in peak discharges due to the accuracy of imperviousness data for a residential area in Boulder, Colorado. It suggested high sensitivity of runoff peak discharge to the accuracy of the imperviousness data. 
In Calgary, Canada, He et al. (2011) investigated climate change impacts on stormwater quantity and quality by using artificial neural networks. In the study, projected daily precipitation and daily average temperature from general circulation models (GCMs) was spatially downscaled using regression based statistical downscaling tool and then incorporated in the network to estimate the changes in stormwater responses. Changes in both stormwater quantity (i.e., runoff volume and peak flow) and quality (i.e., turbidity, conductivity, water temperature, dissolved oxygen and $\mathrm{pH}$ ) were evaluated in the study on event basis in the rainy season. The study found increase in runoff volume and peak flow for most of the events as the rainfall intensity was increased in the future climate scenario. Mixed trends were observed for the water quality parameters for the projected climate scenarios.

Berggren et al. (2011) assessed hydraulic performance of urban stormwater systems in Sweden due to changes in rainfall. Three future rainfall scenarios was derived from regional climate model RCA3 by using delta change method and then evaluated the changes in hydraulic parameters (i.e., number of floods in nodes, frequency and duration of floods, pipe flow ratio) for the study area. The study reported increase in flood frequency, duration, number of flooded nodes as well as extent of floods in the future.

Beling et al. (2011) evaluated sensitivities of SWMM model parameters on both runoff peak and volume for four small periurban basins in Southern Brazil. Basins with grater slope values exhibited higher sensitivity to imperviousness and storage coefficients, while mixed results were found for other parameters depending on the basin's physical characteristics. Yu et al. (2014) also reported high sensitivity of 
stormwater runoff to basin imperviousness in Jinan, China. Although, different studies have focused on estimating stormwater sensitivities to different stressors, their monthly ranges to which they vary over a year, are still unexplored. This research will provide comprehensive estimations of the annual as well as monthly stormwater sensitivities to different major variables, which will facilitate management to design adequate seasonal strategies for efficient stormwater management in similar urban-natural watershed around the world. 


\section{CHAPTER 3}

\section{MATERIALS AND METHODS}

\subsection{Study Basin}

Shingle Creek Basin is mainly a Hydrologic Unit Code (HUC) level -10 basin originally delineated by the US Geological Survey (USGS) (USGS, 2013). USGS divided the whole United States into six levels of hydrologic units ( i.e., HUC 2 to HUC 12) in order to establish a base-line drainage boundary framework. These basins are delineated in a hierarchical scheme with smaller watersheds nested inside larger watersheds. The unit boundaries are defined based on topographic and hydrologic features of an area that drains into a specific outlet point in a stream, river or similar surface waters. It can also indirectly receive water from remnant, noncontributing area. Despite of lakefront or coastal areas, these hydrological units have single flow outlet. A hydrologic unit can only be synonymous with classic watershed when it includes all the contributing sources that drain into a specific outlet point.

The study basin located in parts of Orange and Osceola Counties, comprises of the complex urban-natural watershed of Shingle Creek in Central Florida (Figure 3.1). The northern portion of the basin lies within the corporate limits of the city of Orlando. It mainly consists of one major riverine system "Shingle Creek", which starts from a swamp area in southern Orange County and ultimately drains into Lake Tohopekaliga in Osceola County. It is considered as the northernmost headwaters of the Everglades watersheds. Total drainage area for this creek is around $287 \mathrm{~km}^{2}$. 


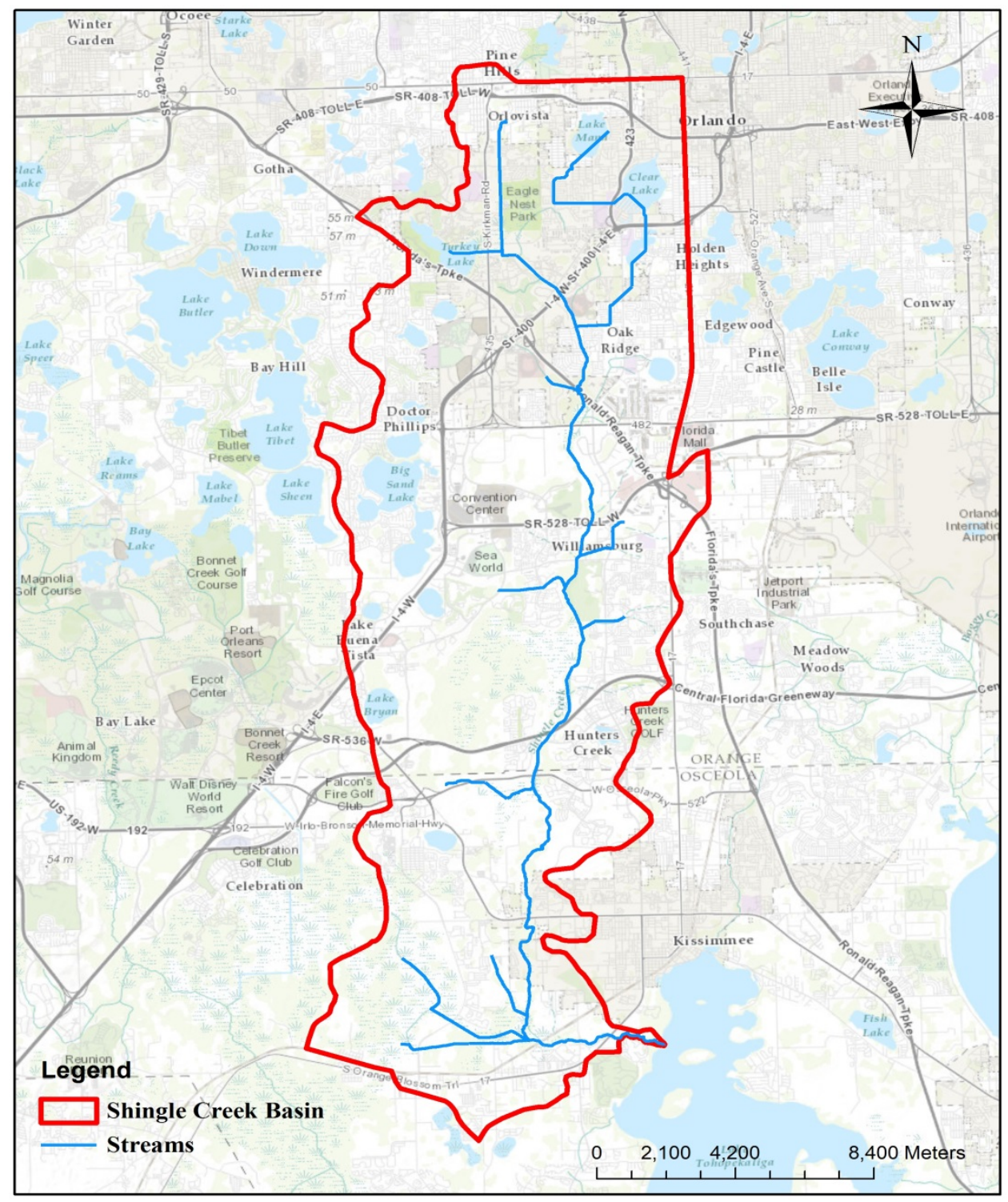

Figure 3.1: Shingle Creek Basin

Shingle Creek watershed is comprised of different land use types. The northern parts of the basin are primarily dominated by medium density residential and commercial developments, whereas the southern portion is a mixture of wetlands and waterbodies. The geology of the region is mainly composed of unconsolidated sandy soils on the surface. The soil type within the watershed is predominantly poorly drained, black to gray sandy soil. The watershed lies within two major physiographic divisions: The 
Central Highlands and the Coastal Lowlands. The Central Highlands include the Mount Dora Ridge and The Orlando Ridge; whereas the Coastal Lowlands include the Osceola Plain. A majority of the Shingle Creek watershed is located within the Osceola plain, which is characterized by very gently sloping, low ridges, with changes in elevation so gradual as to be barely perceptible. The northeastern boundary of the watershed is within the Orlando ridge. The mountain Dora Ridge contains the western boundary of the watershed. The elevation within the watershed varies between $14 \mathrm{~m}$ to $55 \mathrm{~m}$ (relative to the vertical datum, NAVD 1988).

The climate of the basin is characterized by subtropical monsoon climate with long, warm and humid summers with frequent afternoon thundershowers and short and mild winters with very little precipitation. Average temperature of the basin ranges from 81.1 degrees Fahrenheit in summer to 61.1 degrees in winter with annual average temperature of 71.8 degrees. Average annual precipitation of the basin is around 1220 $\mathrm{mm}$. Majority of the rainfall (57\% of the total annual precipitation) occurs during June through September. The basin often experience major rainfall from tropical storms and hurricanes occurred between August and November.

\subsection{Preparation of Datasets}

\subsubsection{Weather Data}

SWMM requires rainfall, evaporation, temperature, wind speed, snowmelt and aerial depletion data for runoff calculation. Air temperature data are only required to simulate snowfall and snowmelt processes. Daily evaporation value for the study area can also be 
simulated by incorporating air temperature data within the model. Air temperature value can be ignored if these simulations are not required for the study area. For evaporation data, it can be fed into the model as single constant value, a set of monthly average values or daily observed values. In this study, evapotranspiration values for Orange County, collected from USGS statewide evapotranspiration data for Florida (USGS Florida Water Science Center Website, 2015) were used. These satellite-based daily evapotranspiration estimates are available for $2 \mathrm{~km}$ spatial resolution for the whole state of Florida. First, grids within Orange County were spatially averaged to estimate monthly average values for a year. Then these monthly values were averaged for 11 years in order to have more representative evapotranspiration estimates for the study area. In this study, average monthly values for 2004-2014 years were fed into the model to account for evapotranspiration effects on runoff generation.

Wind speed data is only required to simulate snowmelt in a study area. It is an optional climate variable. Parameters for snowmelt are used only in a study when it is required to simulate snowfall. It includes air temperature at which rainfall becomes snow, snow surface heat exchange properties and basin characteristics (i.e., elevation, latitude and longitude correction, etc.). To account for non-uniform snowmelt over the surface of a subcatchment, areal depletion parameters are used in the model. As there are no effects of snow on runoff generation for the study area, these climatic variables were ignored in this study. 


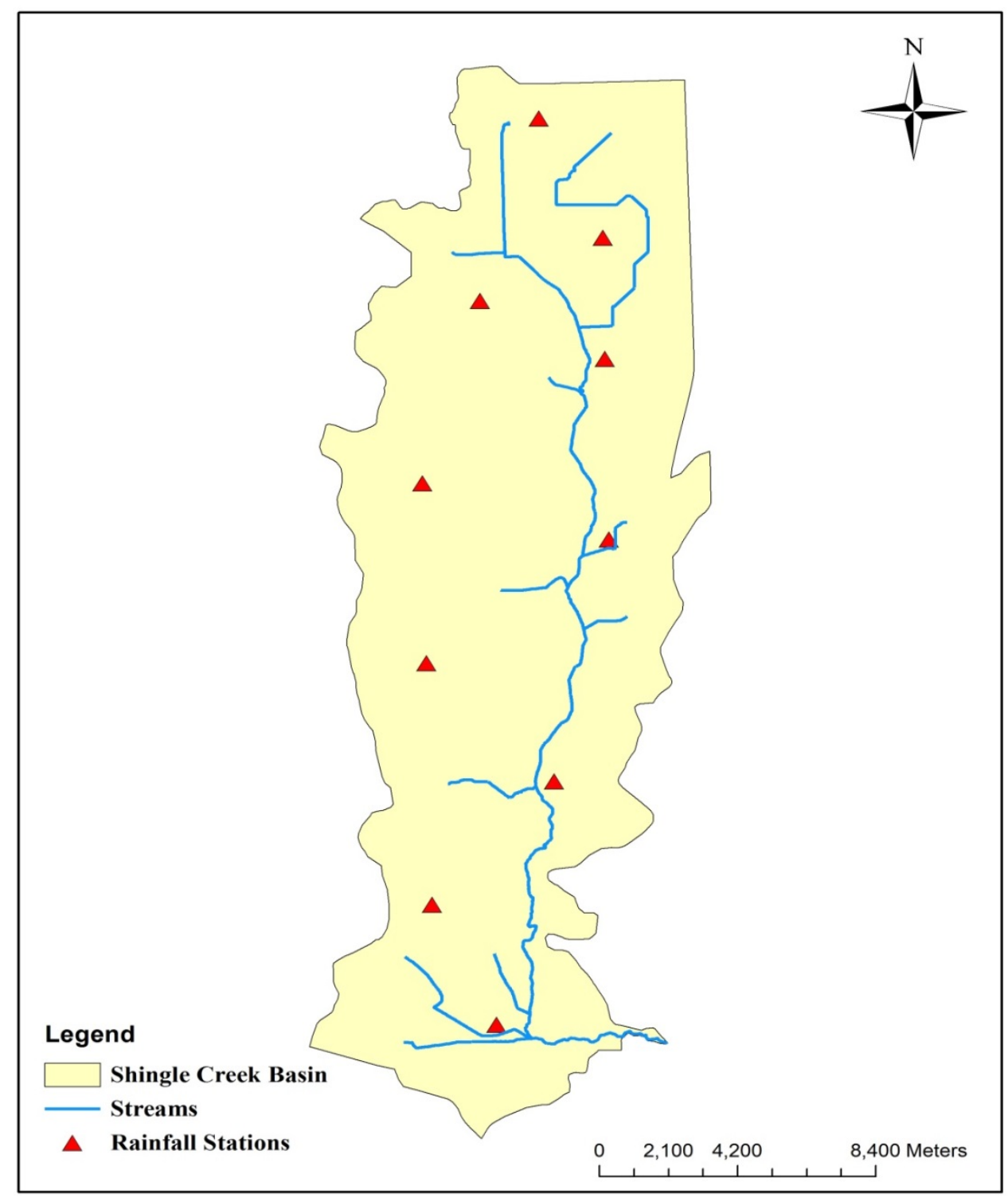

Figure 3.2: Location of rainfall stations

Much precaution was taken in selecting rainfall stations for the study as precipitation is the most important driving factor in generating stormwater runoff. The hourly rainfall data for 2012 and 2013 were collected from NexRad 2 km X 2 Km raingrids as available in the databases of the South Florida Water Management District 
(South Florida Water Management District Website, 2015). Out of many available grids within the study basin, we carefully selected 10 stations (Figure 3.2) for our study in order to ensure spatio-temporal rainfall variability within the watershed. Each subbasin was assigned with one nearby rainfall station for the simulation periods.

\subsubsection{Groundwater Data}

In order to account for ground water contribution into the model, initial groundwater levels (i.e., water table depth) from 8 USGS ground water observation wells for 2012 were incorporated (USGS Water Data for the Nation Website, 2015) (Figure 3.3). Water table depth at subsequent time steps was then updated by the model itself.

While assigning ground water data into the model, it was very important to consider the vertical datum of the source. The model was built based on North American Vertical datum 1988 (NAVD88) which is also the national standard now a day. As the GW elevation data was measured with respect to National Geodetic Vertical Datum 1929 (NGVD 1929), it was very essential to convert the data to NAVD 88. We used VertCon for this purpose which mainly requires latitudes and longitudes of the stations. 


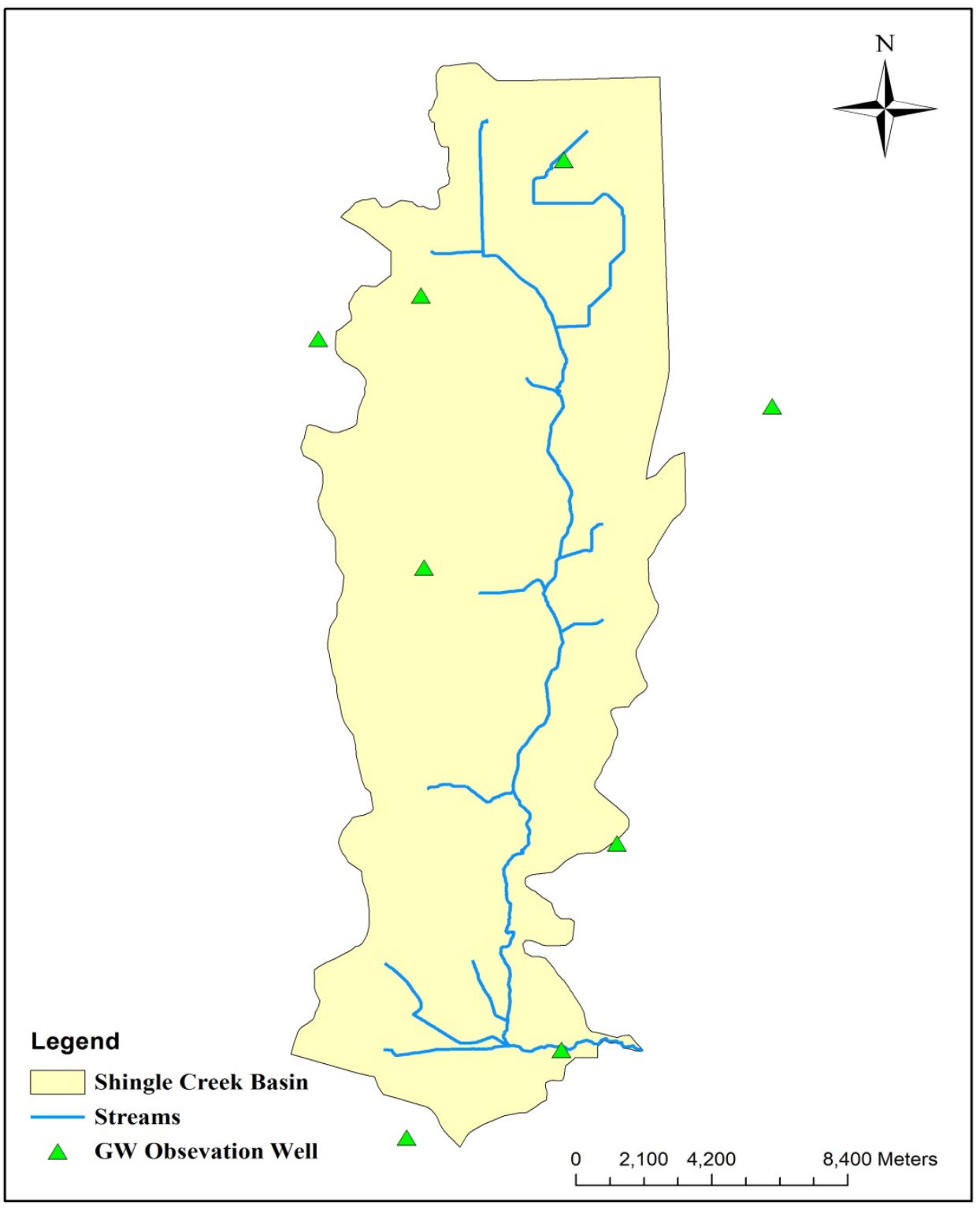

Figure 3.3: Groundwater observation wells used for the model

\subsubsection{Soil Type and Imperviousness Data}

Soil type of the study area is important to parameterize infiltration model in SWMM. Soil type data was downloaded from National Resources Conversation Service (NRCS). Based on the soil type, values for infiltration parameters were assigned into the model 
according to SWMM user manual. These values were later adjusted in order to get good calibration.

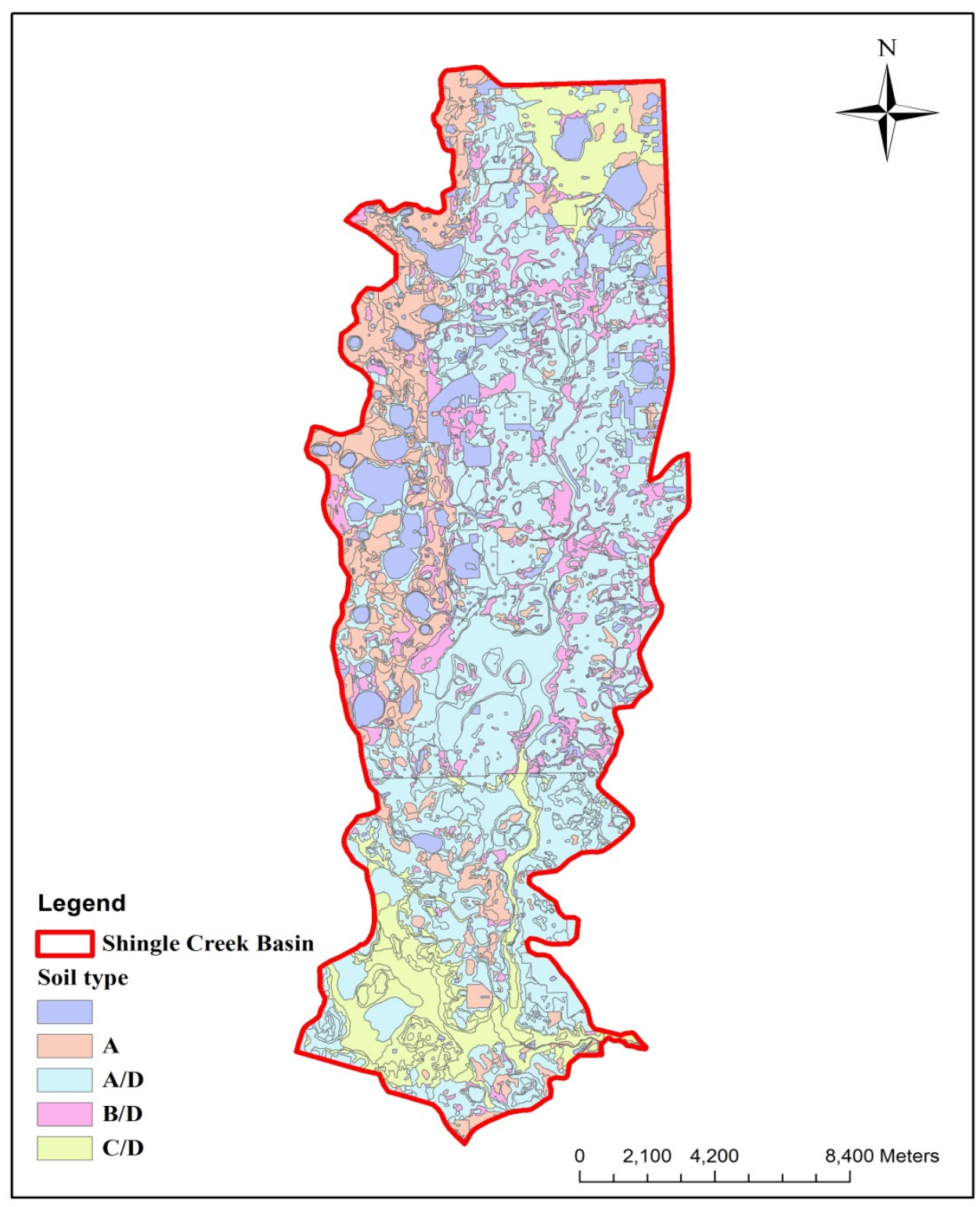

Figure 3.4: Distribution of soil types in Shingle Creek 
Imperviousness of the subbasins plays an important role in generating stormwater runoff. Therefore it is imperative to incorporate accurate percent imperviousness value for each subcatchment into the model. One way to estimate this value by using areaweighted average of the runoff coefficients for different land use types. In our study, this value was calculated from percent imperviousness data acquired from the National Land Cover Database 2011 (National Land Cover Database 2011 Website, 2015).

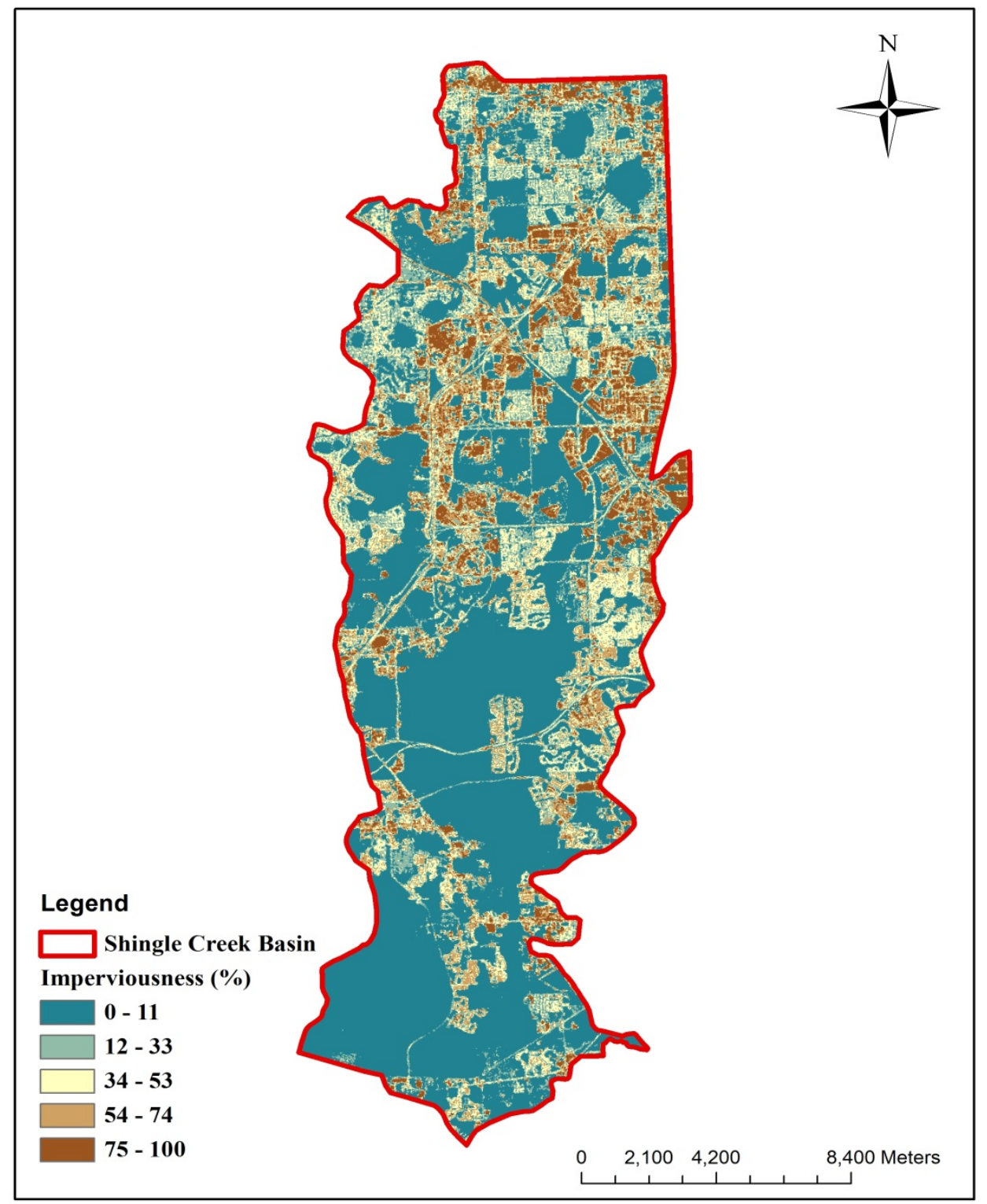

Figure 3.5: NLCD 2011 Percent imperviousness data 


\subsubsection{Stream Flow and Bathymetric Data}

Observed daily stream flow data near the outlet of the basin was obtained from USGS for the years 2012 and 2013. This station was used for model calibration and validation. Stream geometry and bathymetry data (bankfull width and depth, slope) for drainage networks of the study basin were obtained from Kenneth konyha of SFWMD through personal communication. These data were originally collected by field survey for Kissimmee Basin Modeling and Operations Study (KBMOS) project for SFWMD.

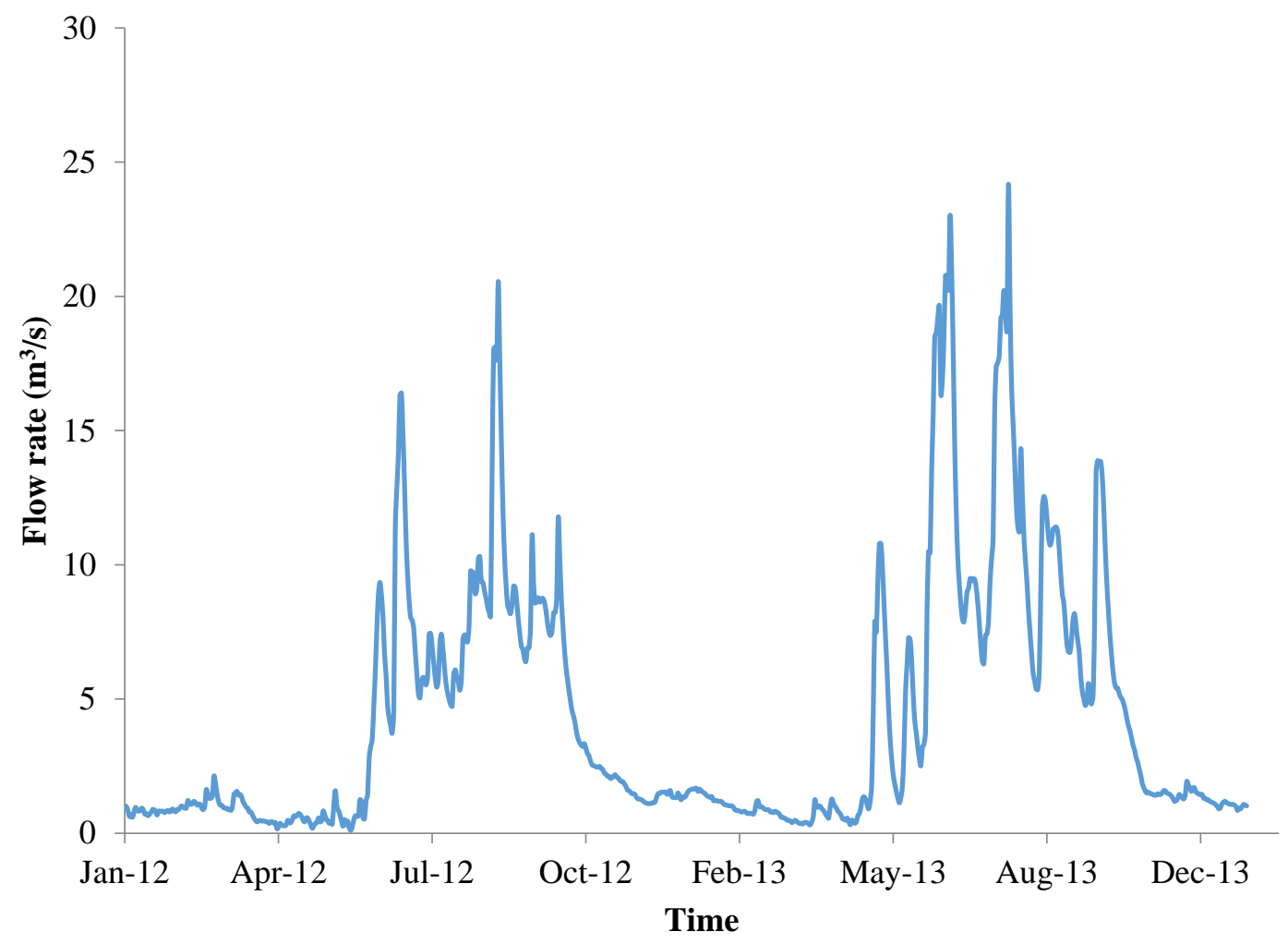

Figure 3.6: Observed daily stream discharge at calibration point for 2012 and 2013 


\subsubsection{Digital Elevation Model}

The digital elevation model (DEM) of $10 \mathrm{~m}$ by $10 \mathrm{~m}$ resolution for the study area was obtained from National Elevation Dataset (NED) of USGS (Figure 3.7). The DEM provides elevation of a particular point with respect to a specific datum. It was used in delineating the subbasins and stream networks within the watershed and also for the analysis of the land surface characteristics.

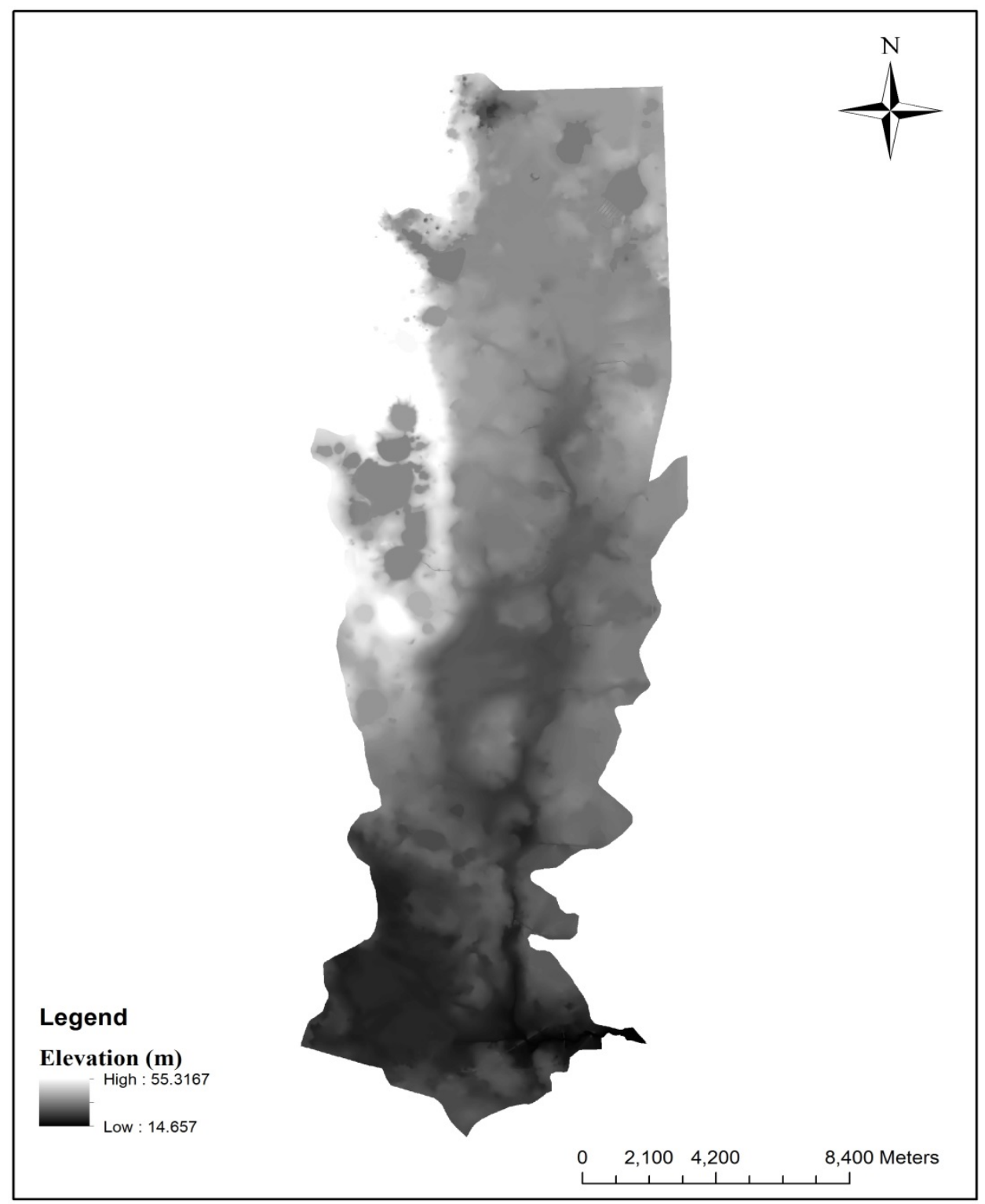

Figure 3.7: Shingle Creek digital elevation model (DEM) 


\subsection{Model Development}

\subsubsection{Storm Water Management Model (EPA SWMM 5.1)}

The EPA Storm Water Management Model (SWMM) can be used to simulate both runoff quantity and quality for single storm event as well as continuous events (long-term) primarily for urban areas (Rossman, 2010). It considers climate, land use, surface and subsurface properties to simulate stormwater runoff quantity and quality. The whole model building process in SWMM can categorized into four basic environmental compartments. They are "Atmosphere”, “Land surface”, “Transportation” and “Groundwater” compartments. SWMM conceptualizes a drainage system as a series of water and material flows between these compartments. The atmosphere compartment includes mainly climate variables such as precipitation and evapotranspiration. Precipitation inputs can be given into the model by using rain gage objects. Different rain gages can be assigned to different subcatchments to ensure spatial variations in rainfall within the watershed. SWMM considers a single dataset for evapotranspiration for the whole study area. Thus it is not possible to assign spatial variations in evapotranspiration for different subcatchments. In this study, monthly average values for ET for the whole study area were fed into the model. SWMM divides the ET according to the time step chosen for the simulation based on the monthly averages. Subcatchment objects in SWMM represent land surface compartment which receives inflow as rain (and/or snow) from atmosphere compartment. Outflow from this component consists of exchange of water with both groundwater compartment (as infiltration) and transportation compartment (as surface runoff and pollutant loadings). These subcatchments in SWMM 
are considered as nonlinear reservoirs where upstream subcatchments can also act as an inflow source to the downstream subcatchment. Surface runoff can only occur when the water depth within a subcatchment exceeds the maximum reservoir capacity. Maximum reservoir capacity for a subcatchment is defined as the summation of total surface storage due to ponding, surface wetting and interception. SWMM uses manning's equation to calculate surface runoff quantity. The runoff algorithm in SWMM can be visualized as shown in the figure 3.8 .

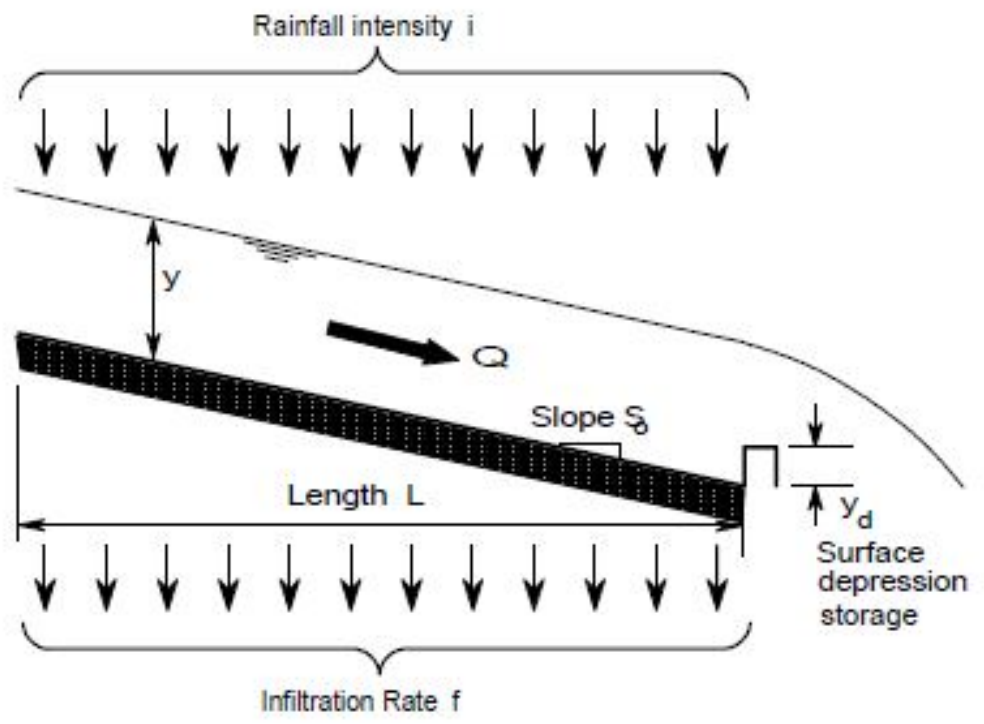

Figure 3.8: Representation of SWMM runoff algorithm (Giron, 2005)

The transport compartment in SWMM is represented through a series of nodes connected by links. The elevation of the drainage system is represented through nodes while links define the conveyance system (e.g., open channels, conduit). Hydraulic routing in SWMM can be modeled using steady flow, kinematic wave or dynamic wave method. For our study, dynamic wave method was chosen for hydraulic routing of the 
conveyance system. For groundwater modeling in SWMM, it uses aquifer objects to reflect the groundwater contribution in stormwater generation. The groundwater compartment receives inflow as infiltration from the above subcatchments and dynamically updates the ground water elevation for the subsequent time steps. It exchanges water with the transport compartment based on the difference in hydraulic heads.

\subsubsection{Model Setup}

We discretized the whole study basin into 66 subcatchments, 53 nodes and 52 links by using the geographic information system (ArcGIS 10.0). Detail discussions on catchment discretization and network delineation along with parameterization are presented in the following sections.

\subsubsection{Subcatchment Discretization and Stream Network Delineation:}

We used 10 m resolution digital elevation model (DEM) to discretize the whole study area into smaller subbasins using ArcGIS platform (ArcGIS 10.0). First, the DEM was

modified by burning actual stream networks downloaded from National Hydrography Dataset (NHD) of USGS using “DEM Reconditioning” tool from ArcHydro. "Fill Sinks”, “Flow Direction” and “Flow Accumulation” tools were then used for terrain processing of DEM. For delineation of stream networks for the study area, "Stream definition" tool was used having a mean drainage area of $1 \mathrm{~km}^{2}$. Later "Stream Segmentation", “Catchment Grid Delineation” and “Catchment Polygon Processing” tools from ArcHydro were applied to divide the whole study basin into smaller subcatchments. 
Finally "Drainage line Processing" and "Drainage Point Processing" tools were used to delineate the stream networks. Afterwards, in order to maintain conformity with the actuals stream network, hypothetical streams delineated by ArcHydro were deleted and the corresponding subbasins were aggregated together maintaining the same drainage outlet point. A total of 66 subcatchments with 52 streams and 53 nodes were delineated by this process for the model development (Figure 3.9).

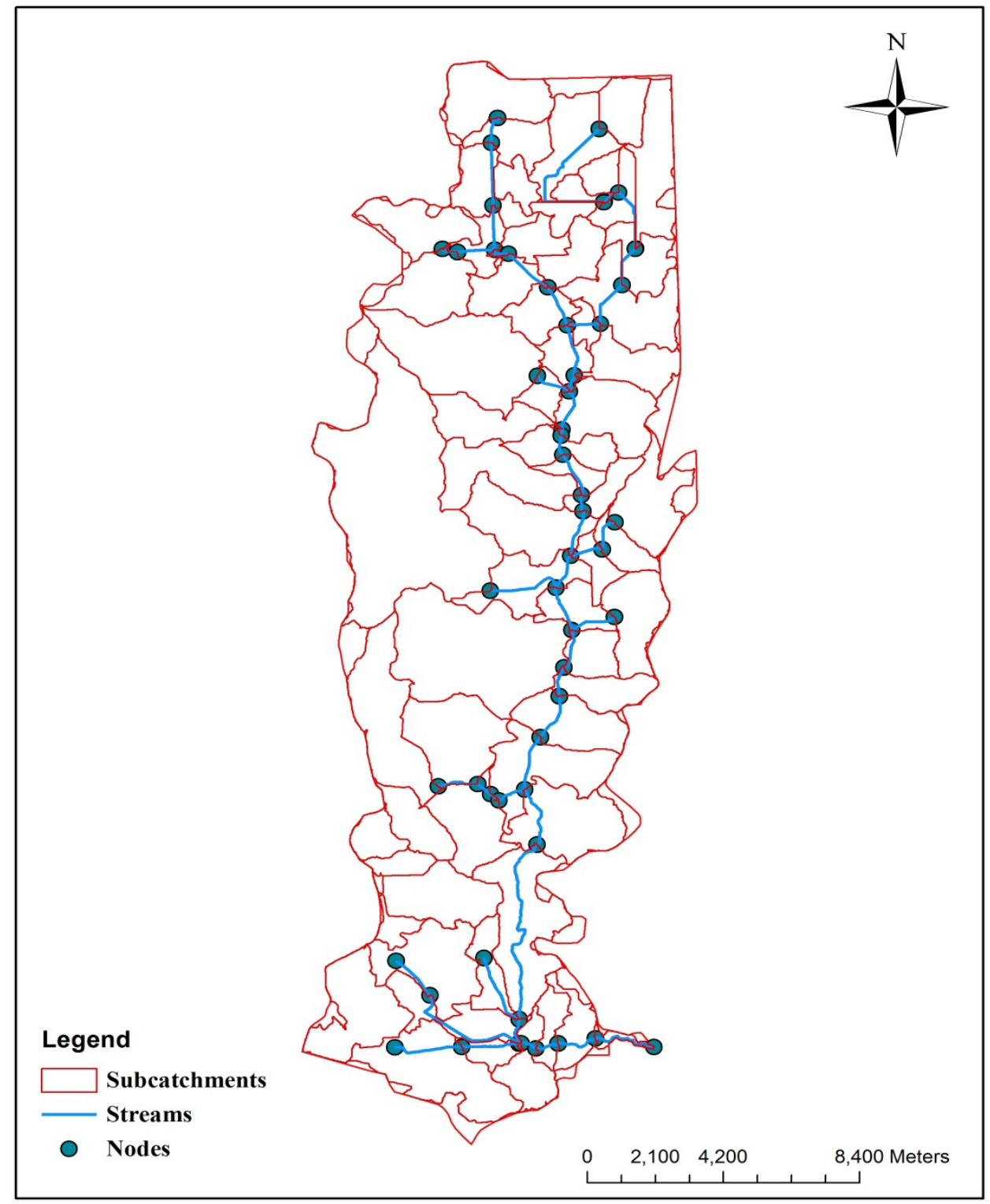

Figure 3.9: Delineated streams, nodes and subcatchments for the model development 


\subsubsection{Subcatchment and Stream Network Parametrization:}

The geographic information system (ArcGIS 10.0) was primarily used for subbasin parameterization. Average slopes of subcatchments were extracted from 10 m DEM (Figure 3.10). Imperviousness of each subbasins were calculated from NLCD 2011 using ArcGIS platform. Storage parameters for pervious and impervious areas were

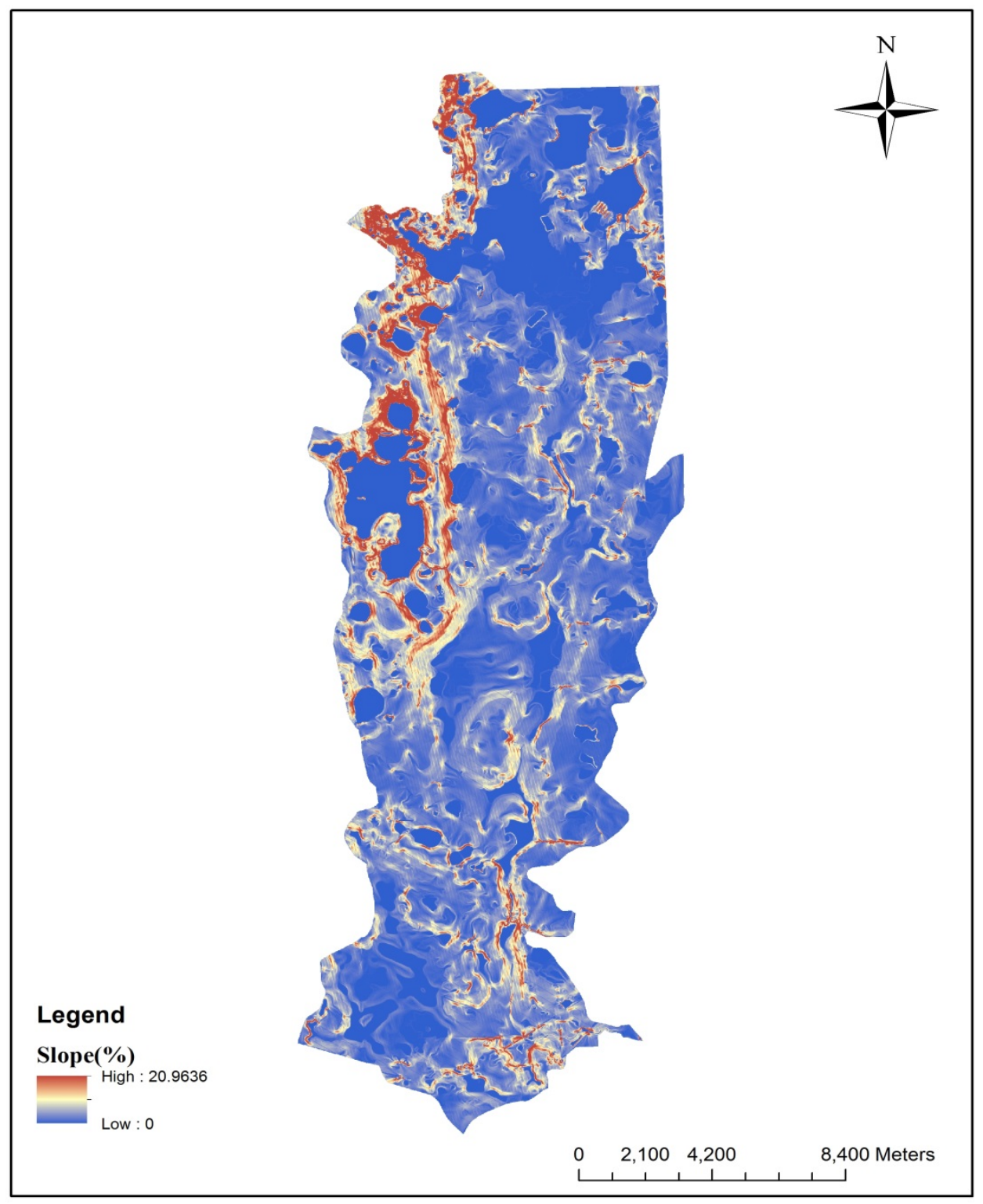

Figure 3.10: Slope of the study area 
assigned into SWMM model as per the manual. Manning's n for pervious and impervious areas were also given as per the instruction. Subbasins width was calculated by dividing the subbasin area with the maximum average overland flow length. According to SWMM application manual by Gironas et al. (2009), it is recommended to consider 500ft maximum overland flow length for natural areas. In our study, initial width for the subcatchments was calculated using 500ft overland flow length. However, these values (width, manning's n, storage parameters) were later adjusted for good calibration. For network parameterization, node's invert elevations were extracted from 10 m DEM. Stream length; co-ordinates of the links and nodes etc. were extracted using ArcGIS platform (ArcGIS 10.0).

\subsubsection{Model Calibration and Validation}

The model was calibrated for 2012 and validated for 2013 with both daily and monthly observed stream flow data near the outlet of study basin, in order to ensure accurate model response (Figure 3.11). Nash-Sutcliffe Efficiency (NSE) and Pearson correlation coefficient (r) were chosen to evaluate the model performance for these time periods. NSE measures the fitness of the simulated values with the observed one by comparing relative magnitude of the residual variance to the measured data variance (Nash and Sutcliffe, 1970). It is defined by the following equation:

$$
N S E=1-\frac{\sum_{i=1}^{n}\left(X_{i, o b s}-X_{i, \text { mod }}\right)^{2}}{\sum_{i=1}^{n}\left(X_{i, o b s}-X_{o b s}^{\text {mean }}\right)^{2}}
$$


Where,

$\mathrm{X}_{i \text {, obs }}=i^{\text {th }}$ observation of the data being evaluated

$\mathrm{X}_{i \text {, mod }}=i^{\text {th }}$ simulated value of the data being evaluated

$\mathrm{X}_{\mathrm{obs}}{ }^{\text {mean }}=$ mean of the observed data

$\mathrm{n}=$ total number of observations

It can ranges from $-\infty$ to 1 , with $\mathrm{NSE}=1$ indicates perfect match between simulated values and observed values. NSE $=0$ indicates the mean value of the observation can be considered as good as the model predictions. NSE $<0$ indicates unacceptable model performance.

The Pearson Correlation coefficient, $\mathrm{r}$ represents the linear correspondence between the predicted and observed data. A value of $r= \pm 1$ represents perfect correlation, whereas $r=0$ refers no correlation. The coefficient was calculated as follows:

$$
r=\frac{\sum_{i=1}^{n}\left(X_{i, \mathrm{obs}}-X_{\text {obs }}^{{ }_{\text {mean }}}\right)\left(X_{i, \mathrm{mod}}-X_{\text {mod } e l}^{{ }^{\text {mean }}}\right)}{\sqrt{\sum_{i=1}^{n}\left(X_{i, \mathrm{obs}}-X_{\text {obs }}^{\text {mean }}\right)^{2} \sum_{i=1}^{m}\left(X_{i, \mathrm{mod}}-X_{\text {mod }}^{\text {mean }}\right)^{2}}}
$$

Where,

$\mathrm{X}_{i, \mathrm{obs}}=i^{\text {th }}$ observation of the data being evaluated

$\mathrm{X}_{i \text {, mod }}=i^{\text {th }}$ modeled value of the data being evaluated

$\mathrm{X}_{\mathrm{obs}}{ }^{\text {mean }}=$ mean of the observed data

$\mathrm{X}_{\text {mod }}{ }^{\text {mean }}=$ mean of the simulated data

$\mathrm{n}=$ total number of observations 


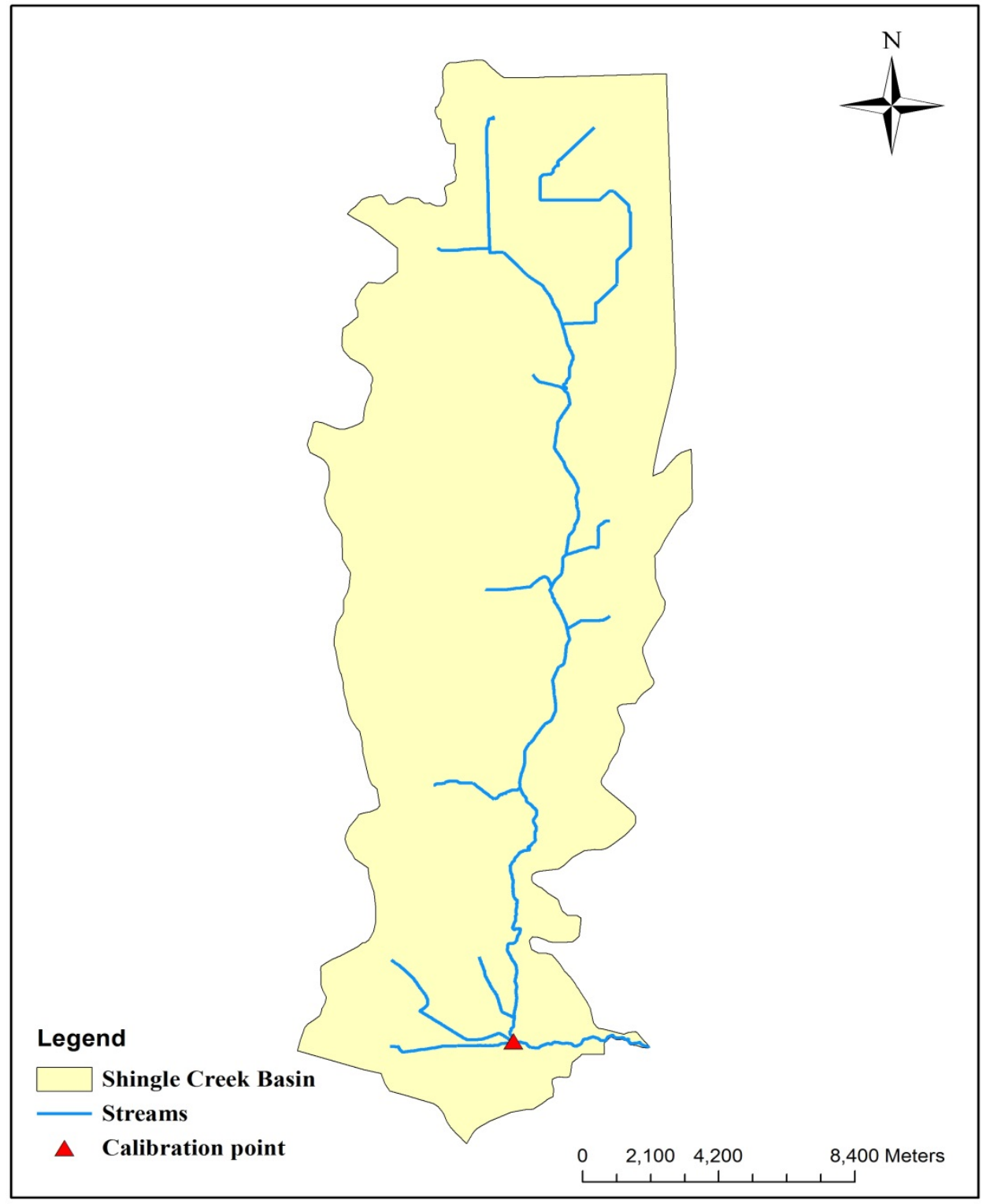

Figure 3.11: Calibration point near the outlet of the basin

The model was calibrated manually for 2012 by changing one parameter at a time. A set of calibration parameters were initially selected for the calibration purpose based on SWMM user manual (Rossman, 2010) and previous studies. Abdul-Aziz and Al-Amin (2014) reported a wide range of parameters that were used for SWMM model calibration in Miami River Basin. Although each basin is unique from hydrological point of view, an 
initial idea for the selection of parameters for calibration purpose was taken from these studies. In this study, parameters for watershed characteristics such as basin characteristics width, roughness and storage coefficient for both pervious and impervious areas considered. Also channel roughness, infiltration parameters for Green-Amp method (i.e., suction head, conductivity and initial deficit of the soil moisture) and groundwater parameters were adjusted to achieve a good calibration. A summary of the adjusted values of the calibration parameters along with model input variables are given in the following table (Table 3.1).

Table 3.1: Ranges of major input parameters and variables into the model.

\begin{tabular}{llll}
\hline Stressor & Parameter & Subbasins & Overall basin \\
\hline Climate & $\begin{array}{l}\text { Hourly Rainfall (mm) } \\
\text { Evapotranspiration (mm/day) }\end{array}$ & $0.25-47.25$ \\
$\begin{array}{l}\text { Hydrology and } \\
\text { Land cover }\end{array}$ & Characteristics width (m) & $1.33-5.38$ \\
& Depression storage (mm) & & \\
& Slope(\%) & $0.05-2.0$ & \\
& Imperviousness(\%) & $0.09-47.44$ & \\
& Overland roughness (Manning's n) & & $0.04^{\mathrm{a}}, 0.15^{\mathrm{b}}$ \\
& Channel roughness (Manning's n) & & 0.02 \\
& Suction head (mm) & & 49 \\
Conductivity (mm/hr) & & 60.2 \\
Initial deficit & & 0.3 \\
Field capacity & & \\
Grountwater flow coefficient & 0.4 & \\
Surface water flow coefficient & 0.01 & \\
Groundwater flow exponent & 0.01 & \\
Surface water flow exponent & 1 & \\
\hline
\end{tabular}

Notes: ${ }^{\mathrm{a}}$ impervious area, ${ }^{\mathrm{b}}$ pervious area. 


\subsection{Sensitivity Analysis}

The primary focus of this research was to determine monthly and annual reference sensitivities of stormwater runoff for Shingle Creek Basin due to changes in major climate and hydrologic variables. Dimensionless sensitivity coefficient as stated by Abdul-Aziz et al. (2010) was used to determine the relative sensitivity coefficients. It indicates both the changes in magnitude as well as direction (i.e., increase or decrease) for the runoff quantity due to changes in model base-line parameters. It can be defined as:

$\mathrm{S}^{*}=\frac{\Delta M / M}{\Delta P / P}$

Where,

$\mathrm{P}=\mathrm{a}$ base value of the model parameter

$\Delta \mathrm{P}=$ change in the base value of the model parameter

$\mathrm{M}$ = base-line model response

$\Delta \mathrm{M}=$ change in model response

The developed model simulated surface runoff for each subbasin in an hourly time step. Basin total runoff was computed by summing all the hourly runoffs over the year for all subbasins and then reported in monthly and annual scales in order to determine relative sensitivities of the stormwater runoff. 


\subsubsection{Sensitivity Scenarios and Selected Parameters:}

The study computed both individual and combined sensitivities of stormwater runoff for the calibration year 2012. Two climatic variables i.e. precipitation and evapotranspiration and three hydrologic and land cover variables i.e. imperviousness, slope, and basin roughness (manning's n) were considered for the study. For individual sensitivity analysis, parameters were altered one at a time whereas combined sensitivity was calculated by changing multiple parameters simultaneously. Precipitation as one of the major climatic drivers of stormwater runoff was amplified by 5 to 20 percent (at $5 \%$ increment) from the base value. Monthly evapotranspiration values were also altered to the same range (i.e., $5,10,15$, and $20 \%$ ) to see the effects of global warming on runoff generation. These scenarios were selected based on anticipated changes in precipitation and evapotranspiration in next decades as reported by Obeysekra et al., 2011. The study reported around $10 \%$ expected change (increasing/decreasing) in annual regional precipitation, while up to $10 \%$ increase in evaporation by 2050 . Percent imperviousness of the subbasins mainly refers to the land cover types of the study area. Due to increase in population and corresponding urbanization, 4 sensitivity scenarios (an increase of 10, 20, 30, and $40 \%$ from base value) for imperviousness were considered. Stormwater sensitivities to basin's slope and roughness were also evaluated by increasing their baseline values by 20\%. Basin's roughness parameters in SWMM mainly represent stormwater management practices such as Low impact development (LID).

The study also revealed combined effects of rainfall, imperviousness and evapotranspiration on runoff generation by considering multiple scenarios at a time. The 
combined scenarios were reported for annual changes in runoff rather than on monthly basis to estimate combined hydro-climatic and land cover effects for the study basin. 


\section{CHAPTER 4}

\section{RESULTS AND DISCUSSION}

\subsection{Model Evaluation}

The model was calibrated and validated for the year 2012 and 2013 respectively, with both mean daily and monthly observed streamflow near the outlet point. Calibration is the process of adjusting the assumed model parameters within their acceptable range in order to have a better match between the model predictions and the observed or measured values. Validation insures the capability of a site-specific model to simulate future scenarios under the same set of parameters that were obtained through calibration process. Different statistical measures can be used to determine the robustness of a model in simulating the scenarios. In this study, Nash-Sutcliffe Efficiency (NSE) and Pearson's

correlation coefficient (r) were used to evaluate different datasets (observed and simulated) in the calibration and validation periods.

For the calibration year 2012, Nash-Sutcliffe Efficiency (NSE) and Pearson's correlation coefficient (r) were 0.41 and 0.70 , respectively, with mean daily observed stream flow (Figure 4.1). With monthly average flowrate for the same calibration year, the NSE and r values increased to 0.54 and 0.85 (Figure 4.2), which indicates the model is a better predictor for monthly scale than the daily scale. The increased NSE and $r$ values for the monthly scale were expected as both the observed and simulated values were averaged over the month, and thus it muted the daily variations. 


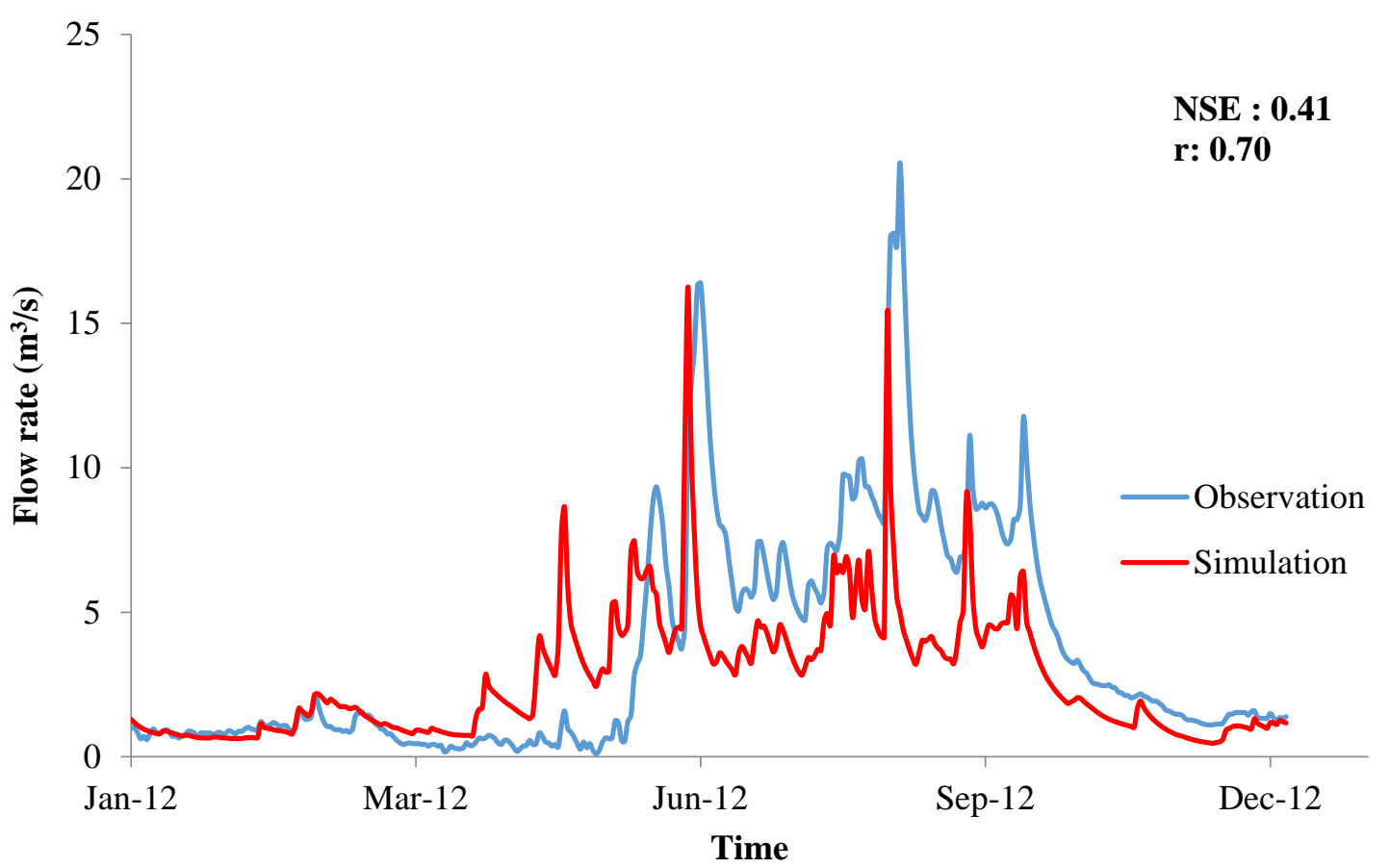

Figure 4.1: Observed vs Simulated mean daily stream discharge for 2012

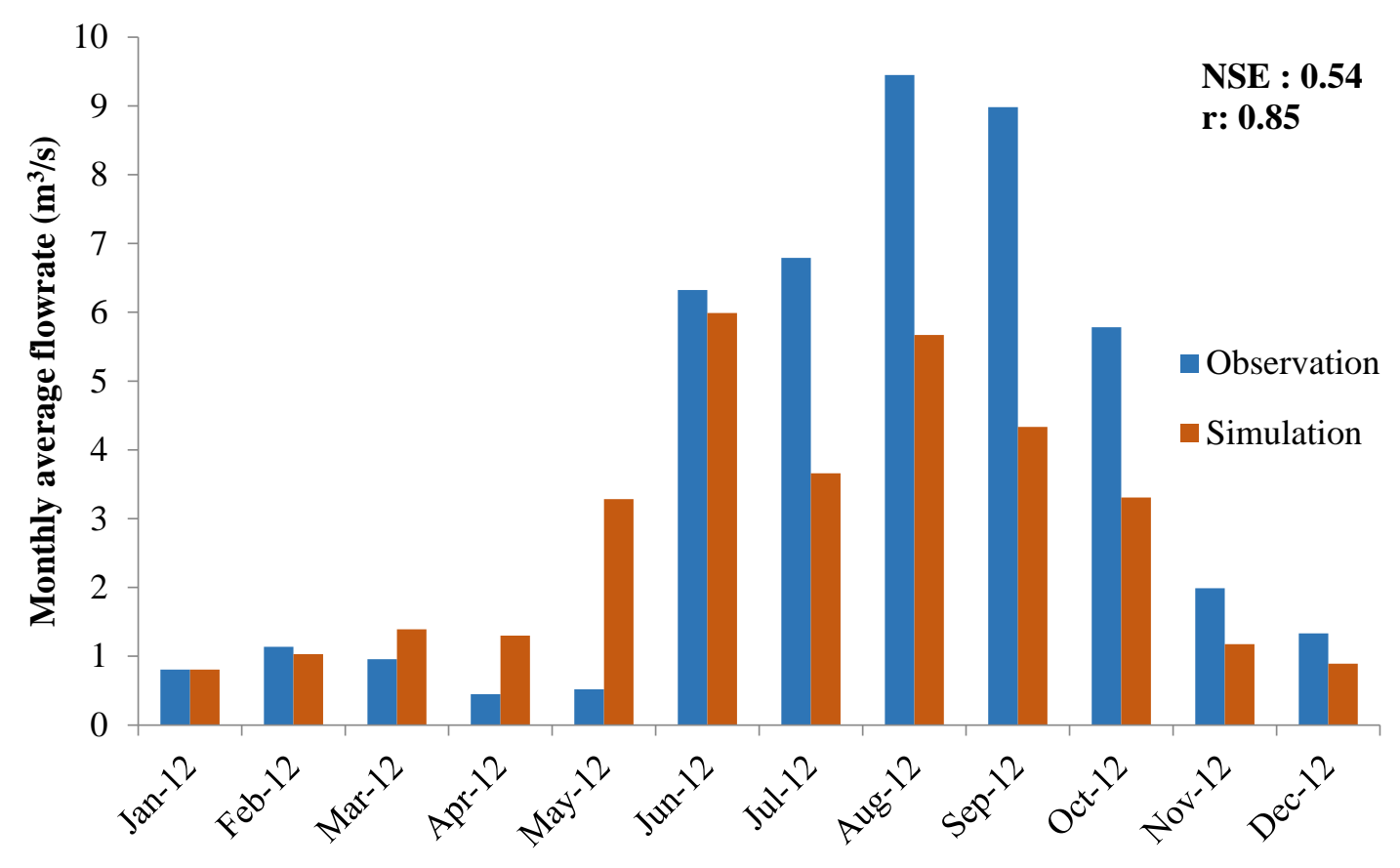

Time

Figure 4.2: Observed vs Simulated mean monthly stream discharge for 2012 


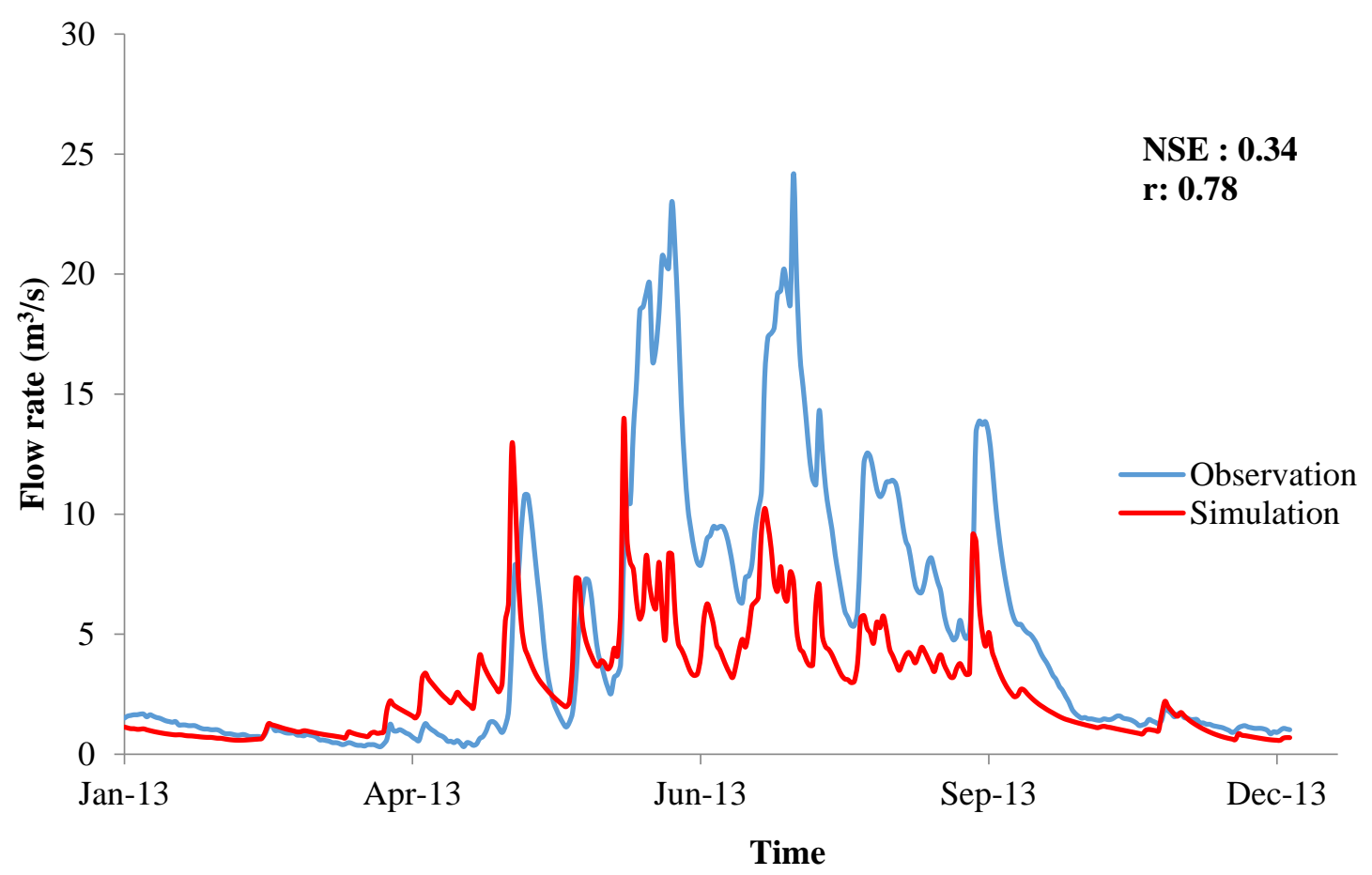

Figure 4.3: Observed vs Simulated mean daily stream discharge for 2013

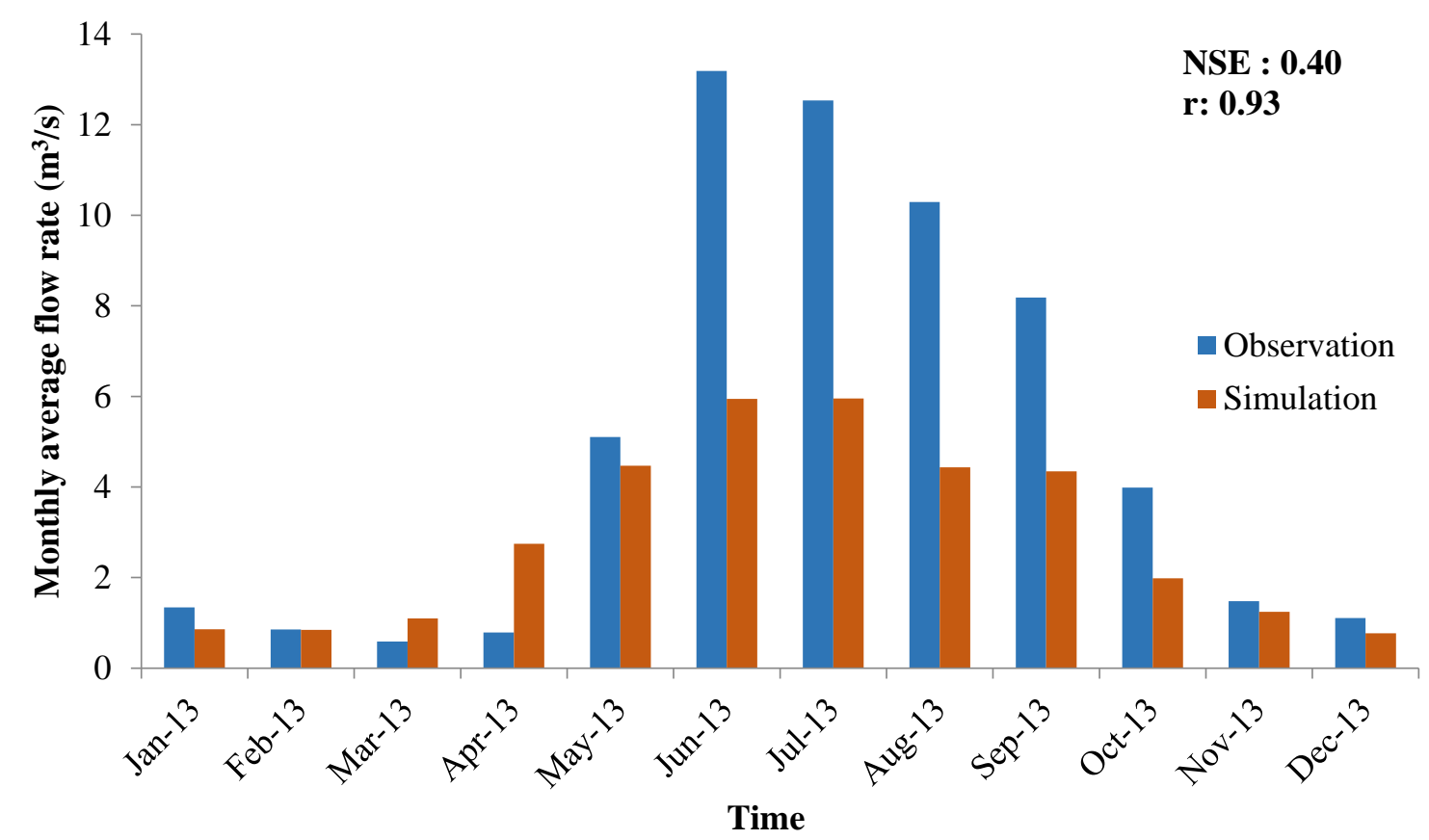

Figure 4.4: Observed vs Simulated mean monthly stream discharge for 2013 
For the validation year 2013, the NSE and $r$ values were 0.34 and 0.78 respectively, with mean daily observed stream flow (Figure 4.3). With monthly average flowrate, the values increased to 0.40 and 0.93 (Figure 4.4), respectively, as expected. The relatively lower NSE value for the validation year might be due to short calibration period of the model which might restrict it to fully capture the long-term hydrological variabilities for the study area.

\subsection{Sensitivity Analysis}

The study evaluated dimensionless monthly and annual stormwater sensitivity coefficients for two major hydro-climatic (i.e. rainfall and evapotranspiration) and three land cover and hydrologic variables (i.e. imperviousness, basin roughness and slope) for the calibration year 2012. Individual sensitivities were estimated for all the parameters whereas three major variables (i.e., rainfall, imperviousness and evapotranspiration) were selected for combined scenario analysis for this study. The following sections reported relative changes in runoff due to changes in variables instead of reporting dimensionless sensitivity coefficients as examples.

\subsubsection{Hydro-climatic Sensitivities}

\subsubsection{Rainfall}

In this study, rainfall was increased by $5 \%$ to $20 \%$ (at 5\% increment) from the baseline 2012 rainfall, while the number of rainfall events and the rainfall durations were considered unchanged. Much temporal variations in the monthly rainfall were observed in Shingle Creek Basin for the year 2012 (Figure 4.5). Maximum rainfall occurred in 
June (307 mm), while May, July, August, September and October experienced high rainfall amounts. November to April received lower rainfalls compared to other months. In Shingle Creek, high and notable different monthly stormwater sensitivities to rainfall were observed due to changes in baseline rainfall, although runoff increased almost linearly in each month (Figure 4.6). Runoff in January and May showed maximum sensitivities to rainfall, while, minimum change in runoff was observed for February. Runoff in other wet months such as June, July, August, September and October showed moderate to high sensitivities (7\% to 30\%). In November, December, March and April, potential stormwater exhibited relatively lower changes compared to other months. Annual total runoff increased by $7 \%$ to $29 \%$ due to $5 \%$ to $20 \%$ increase in rainfall amounts.

Variation in both rainfall amounts (i.e. intensities/depths) and number of events in different months caused differences in soil moisture conditions over the year and, thus resulted differential monthly runoff sensitivities. May experienced 36 (average over the basin) hourly, distributed, moderate to high depth rainfall events in 2012. The distribution of rainfall events along with depth might cause highest runoff sensitivities (7-31\%) for May as the soil was already saturated and increase in rainfall amounts caused higher runoff generation. This explanation is also applicable for other wet months (June to October) as they also experienced similar rainfall pattern over the month. In January, the basin received 7 (average over the basin) low intensity rainfalls, concentrated in 3-4 days only, which led to minimum base-line runoff. Amplifying rainfall amounts by $5 \%$ to $20 \%$ thus have caused highest relative increases (8-31\%, respectively) for January runoff. 


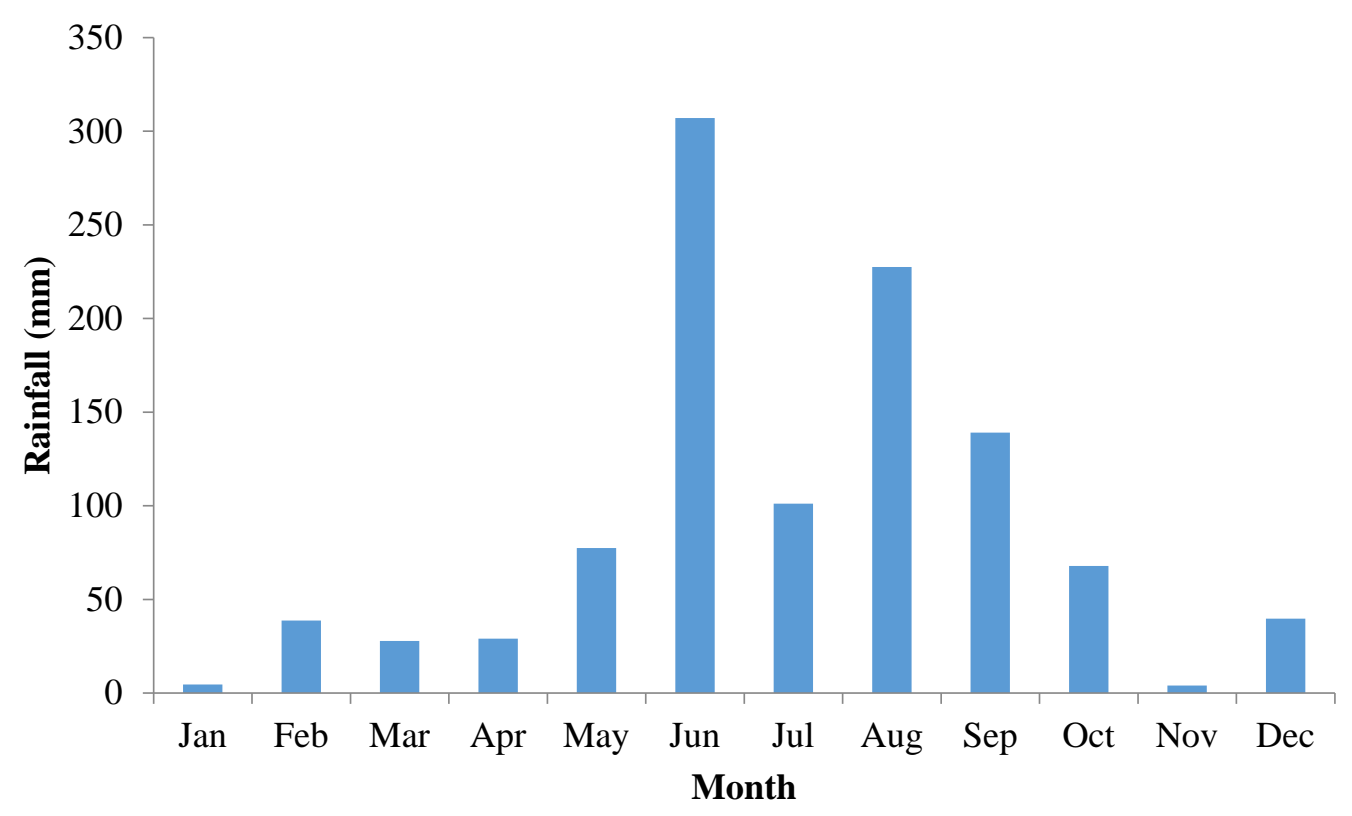

Figure 4.5: Monthly average rainfall of 2012 in Shingle Creek Basin

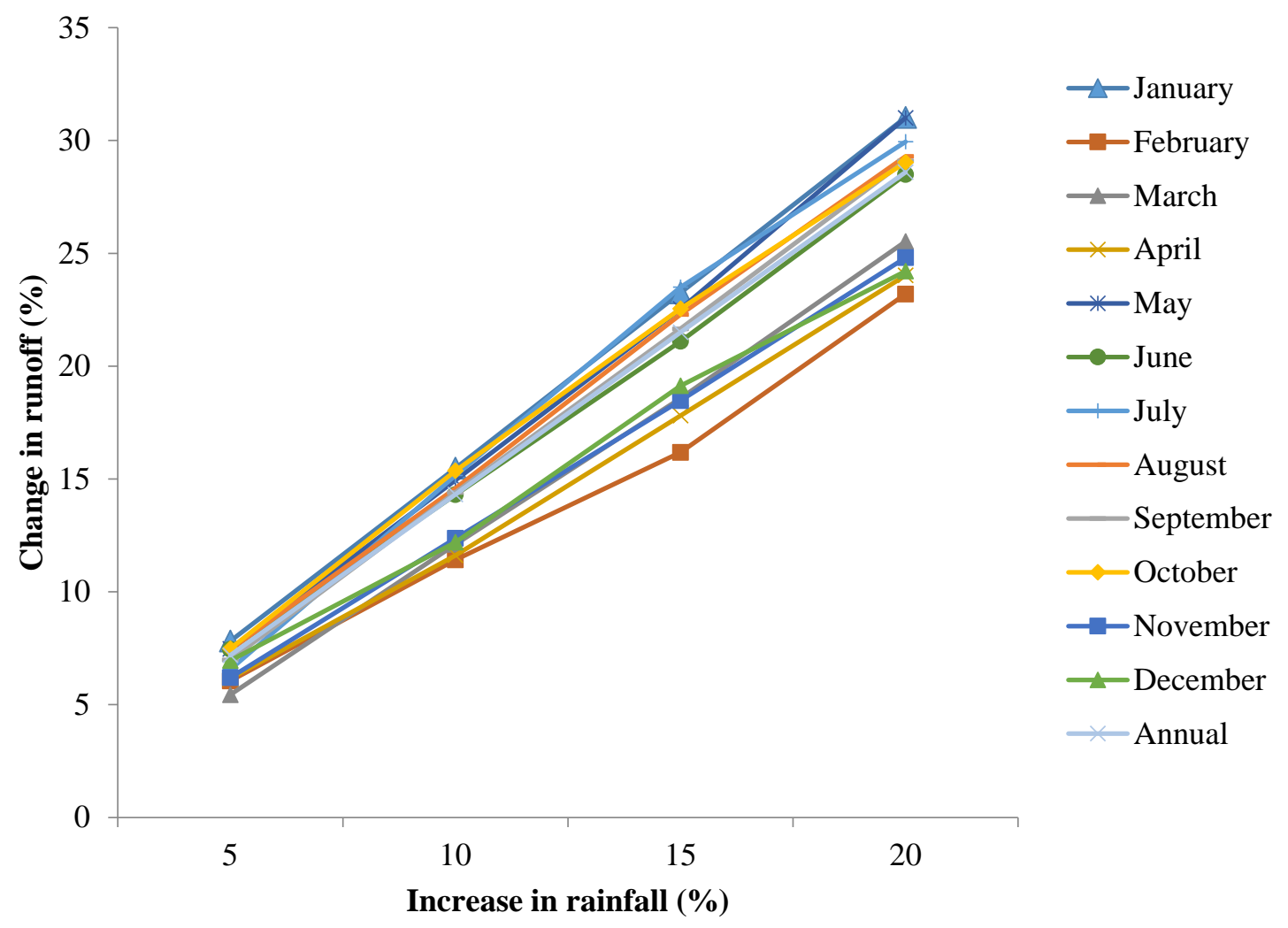

Figure 4.6: Changes in runoff for different changes in rainfall 
Although November received almost equal total amount of rainfalls $(4 \mathrm{~mm})$ as that of January, the relative changes in stormwater were less (6-25\%, respectively) as the rainfall events were distributed in more days (6-7 days). February experienced much higher intensity rainfall compared to January, leading to much higher base-line runoff and, thus exhibited lowest runoff sensitivities (6-23\%). Runoff in other dry months (December, March and April) showed relatively low to moderate sensitivities (5-26\%) to rainfall changes.

\subsubsection{Evapotranspiration}

The model was run by changing average monthly evapotranspiration values by 5 to $20 \%$ (at 5\% increment) to quantify evapotranspiration effects on stormwater runoff for Shingle Creek Basin. Evapotranspiration showed opposite and less sensitivity on stormwater runoff compared to rainfall. Monthly average evapotranspiration for the Shingle Creek Basin ranges from $1.33 \mathrm{~mm} /$ day to $5.38 \mathrm{~mm} /$ day (Figure 4.7). Maximum evapotranspiration occurred in June whereas minimum evapotranspiration was seen for December. Runoff in February exhibited minimum relative sensitivities, while maximum sensitivities were seen for January runoff (Figure 4.8). These results are analogous to the rainfall sensitivities as runoff in February and January also showed minimum and maximum relative changes to rainfall. January generated low baseline runoff compared to February due to low intensity rainfall and number of events. As both the months exhibited relatively low evapotranspiration rates, the relative changes in stormwater runoff were highest for January and lowest for February. Runoff in other dry months (i.e., November, December and April; except for March) showed relatively low sensitivities to 


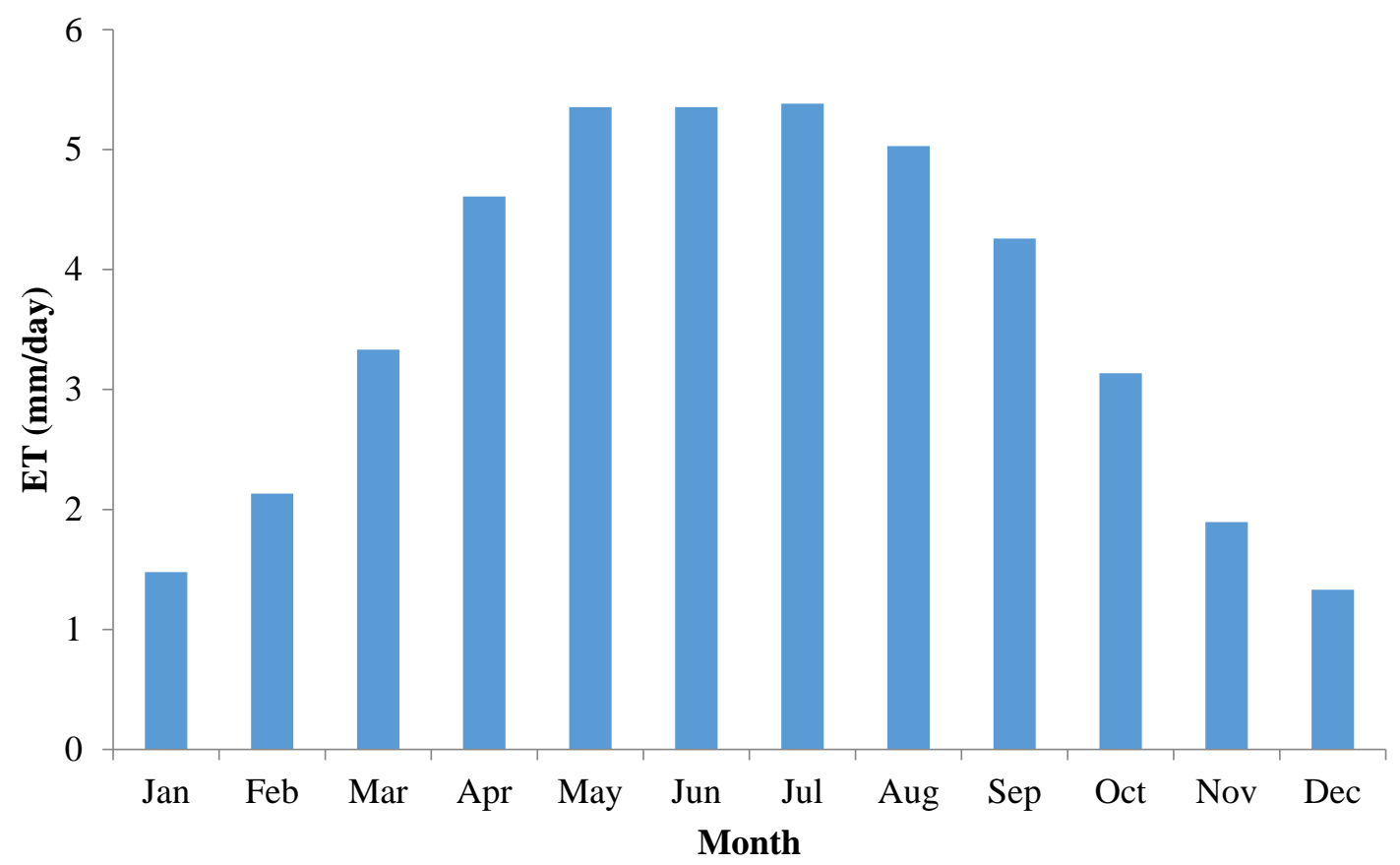

Figure 4.7: Monthly average evapotranspiration (2004-2014) in Shingle Creek Basin

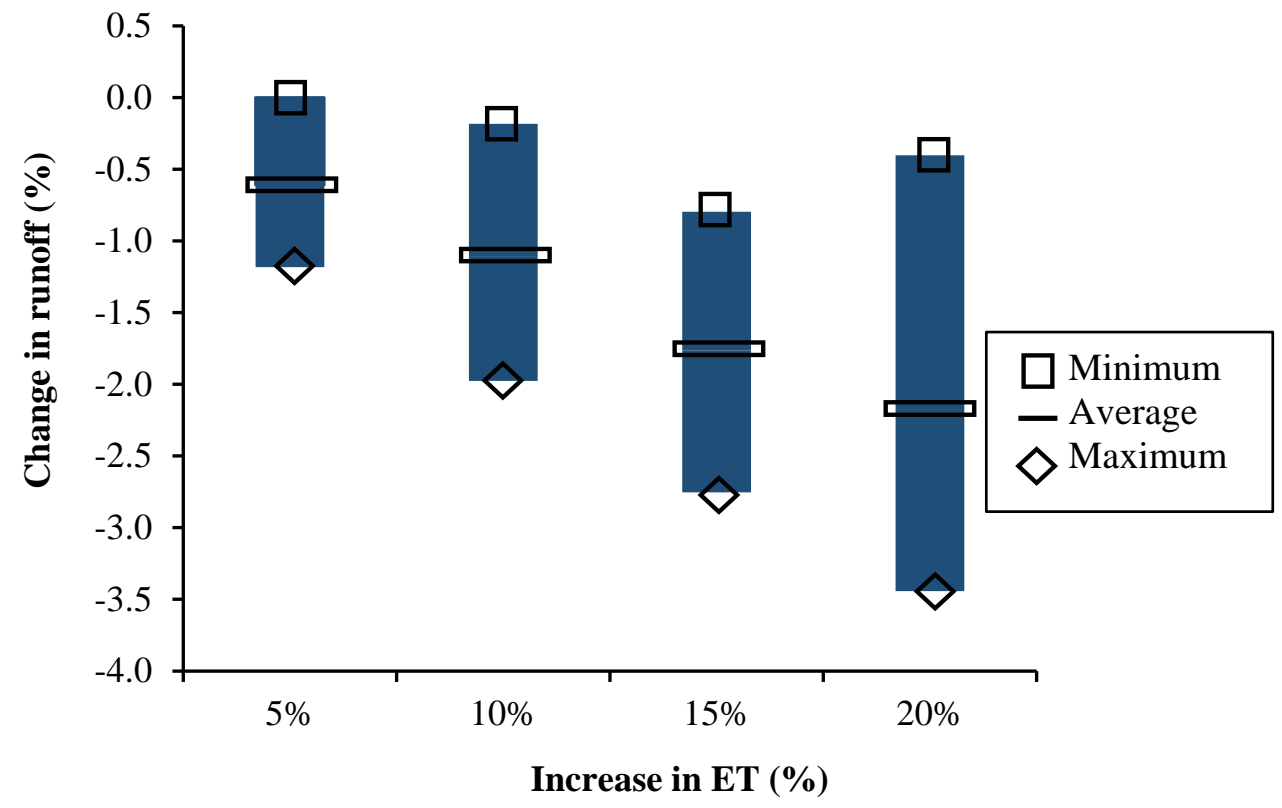

Figure 4.8: Changes in runoff for different changes in evapotranspiration 
evapotranspiration compared to other months. Average monthly runoff changes due to increase in evapotranspiration ranges from $0.61 \%$ to $2.17 \%$. Overall, stormwater runoff in Shingle Creek Basin is strongly dictated by rainfall variability rather than changes in evapotranspiration.

\subsubsection{Land Cover and Hydrologic Sensitivities}

\subsubsection{Imperviousness}

Monthly and annual stormwater sensitivities to imperviousness were evaluated by increasing imperviousness parameter by 10 to $40 \%$ (at $10 \%$ increment) from the base line value. The analysis showed different monthly runoff sensitivities to imperviousness (Figure 4.9) over the year. Runoff in February showed maximum sensitivities (10\% to $39 \%$ ), while in June; it showed minimum sensitivities (6\% to 21\%) for the aforesaid changes in imperviousness. Runoff in drier months (i.e., November to April) showed relatively higher sensitivities to imperviousness than the wetter months (i.e. May to October). These phenomena can also be explained by the temporal variations of rainfall in concert with resulting soil saturation of the basin. As the imperviousness of the subbasins were amplified while keeping the rainfall events and amounts unchanged, higher runoff sensitivities were observed for those months where rainfall caused early soil saturation and filling up of the depression storage. For example, February received moderately high amounts of rainfall distributed over the month which generated high amount of baseline runoff compared to other dry months. Increase in imperviousness caused early soil saturation as well as filled up of the depressions, which generated 


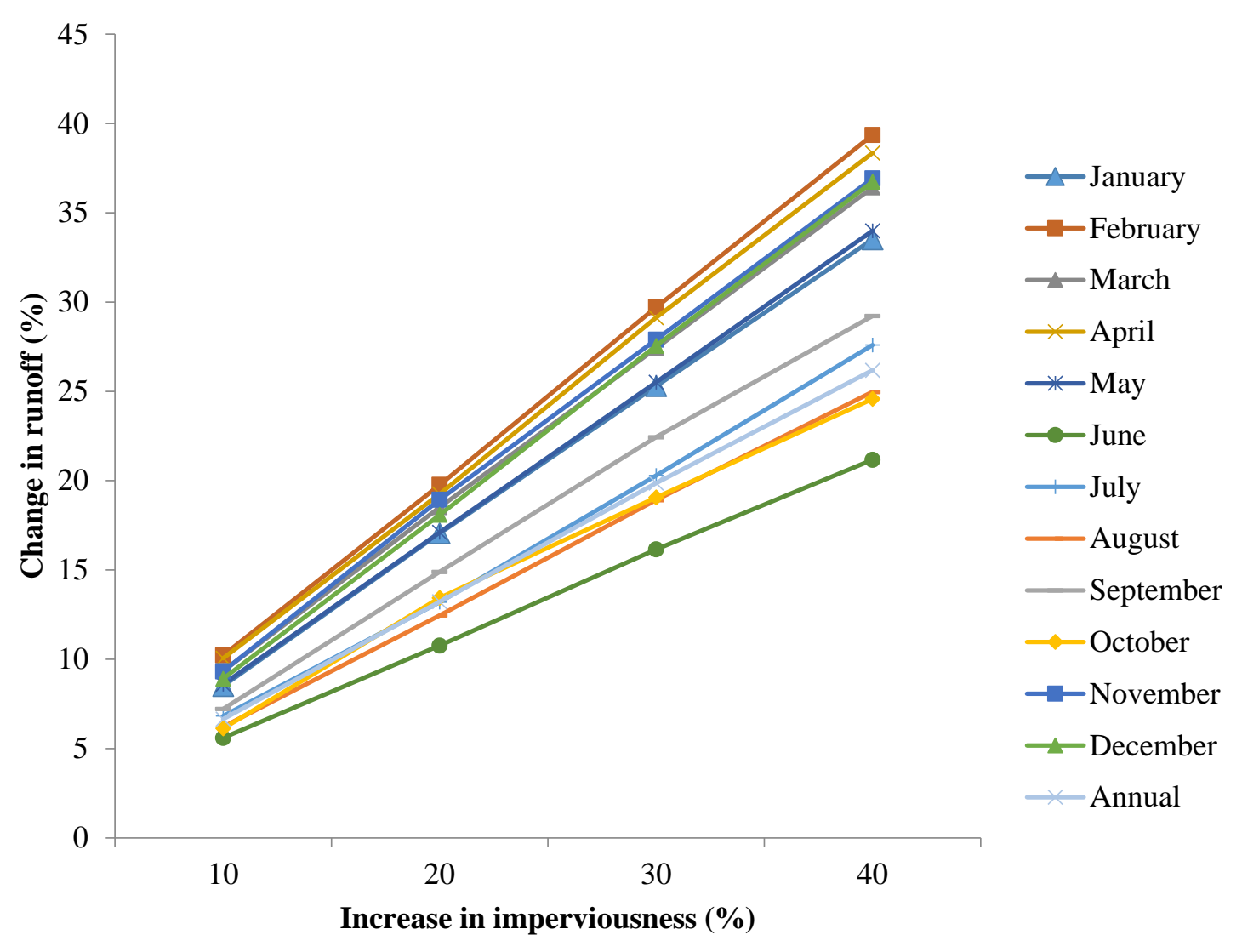

Figure 4.9: Changes in runoff for different changes in Imperviousness

relatively high amounts of runoff for the month. Other dry months also experienced the same phenomena. For June, it experienced highest rainfall amount in 2012, generated maximum baseline runoff for the study basin. Increase in imperviousness caused increase in runoff in June, although the relative increase was lowest compared to other months. Runoff in other wet months also exhibited low to moderate sensitivities to imperviousness due to high base-line runoff amount. Annual runoff sensitivities to imperviousness for the study basin range from $7 \%$ to $26 \%$ due to increase in imperviousness by $10 \%$ to $40 \%$, respectively. 


\subsubsection{Basin Roughness and Slope}

In order to see the effects of green developments and basin's slope on stormwater runoff, both the coefficients, overland manning's n and basin's slope were amplified by $20 \%$ from their base-line values. Basin roughness had a negative effect on stormwater runoff, whereas slope had a positive effect. Changes in both the parameters showed relatively low changes in potential runoff compared to imperviousness. Increase in basin roughness by $20 \%$ decreased average monthly runoff by around $1 \%$ only (Figure 4.10 ). For monthly variations (not shown), runoff in January showed maximum changes to roughness (2.89\%), while February runoff exhibited lowest sensitivity (0.04\%). Wet months (May to October) runoff showed relatively low to moderate sensitivities to basin roughness. The low changes in potential runoff due to changes in basin roughness can be attributed to the land use types of the study basin. Total runoff changes for changes in overland roughness were muted mainly because of the presence of large natural areas within the watershed. Natural parts of the study basin produced lower amounts of runoff compared to the urban portion, and thus when the results were reported for the whole study area, it smoothen the effects of roughness coefficient on runoff generation. Like basin roughness, runoff was also less sensitive to basin's slope (Figure 4.7). Low sensitivities to basin slope can be attributed to the flat topography of the study area (Slope varies from 0.05 to $2 \%$ within the watershed). Increase in basin slope by $20 \%$ led to increase average monthly runoff by only $0.66 \%$. Maximum change in runoff was observed for January, while minimum was seen for June. As the base-line runoff for dry months were relatively low compared to wet months, higher sensitivity were observed for dry months. 


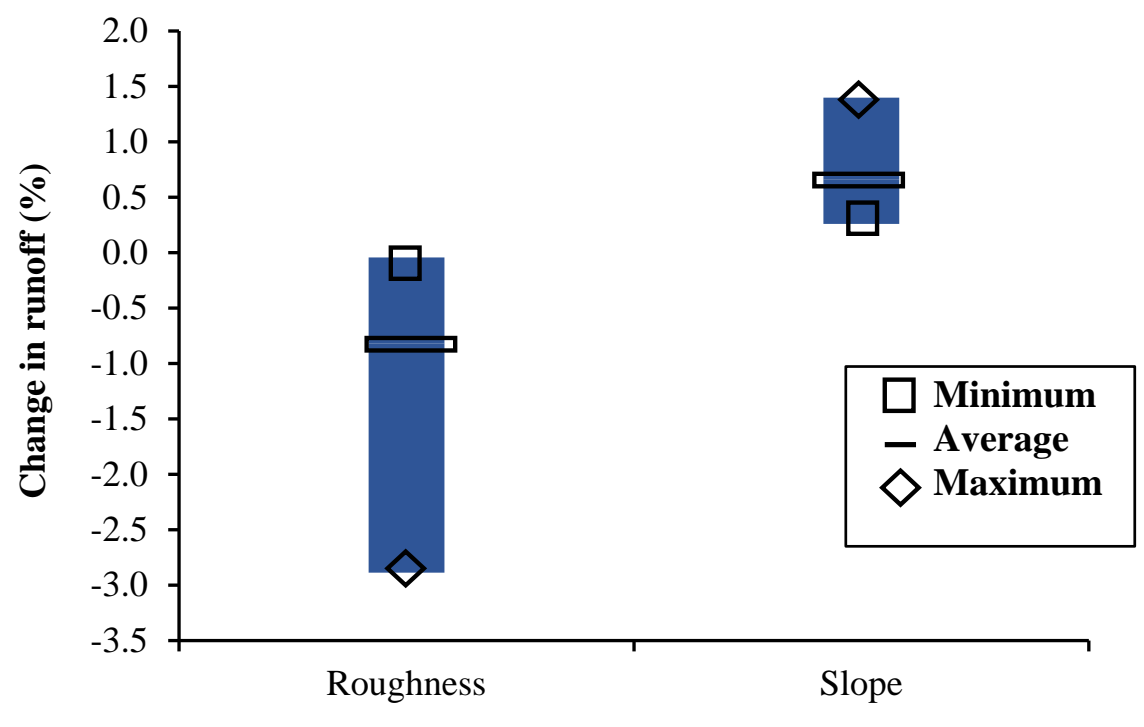

$20 \%$ increase in parameters

Figure 4.10: Changes in runoff for $20 \%$ increase in roughness and slope

\subsubsection{Combined Hydro-climatic and Land Cover Sensitivities}

The sensitivity analysis for different climatic, land cover and hydrologic variables reveled that; stormwater was highly sensitive to rainfall and imperviousness, whereas evapotranspiration, basin slope and roughness showed low to moderate sensitivities. In the study, evapotranspiration, imperviousness and rainfall were increased simultaneously to see the climate change and urbanization effects on stormwater runoff generation for the study basin. Evapotranspiration and rainfall were increased by 5 to 20\% (at 5\% increment) whereas imperviousness was increased by 10 to $40 \%$ (at $10 \%$ increment). The following sections discussed potential changes in annual runoff due to simultaneous changes in rainfall, evapotranspiration and imperviousness for the study area. 


\subsubsection{Combined Rainfall and Evapotranspiration Sensitivities:}

Annual runoff increased due to increase in rainfall and decreased due to increase in evapotranspiration, as expected (Figure 4.11). For example, when rainfall standalone increased by $20 \%$, annual runoff increased by around $29 \%$ compared to baseline runoff of 2012. For evapotranspiration, when it was increased by $20 \%$ in the model keeping the rainfall unchanged, it decreased the annual runoff by $2.4 \%$ for the study area. But when rainfall and evapotranspiration were increased by $20 \%$ and $20 \%$ simultaneously, total runoff was increased by 25\%, which is slightly less than their individual linear summation (26\%). A plausible explanation of these different sensitivities is that, due to increase in both rainfall and evapotranspiration at the same time, much higher evapotranspiration occurred and thus generated slightly less surface runoff for the study area.

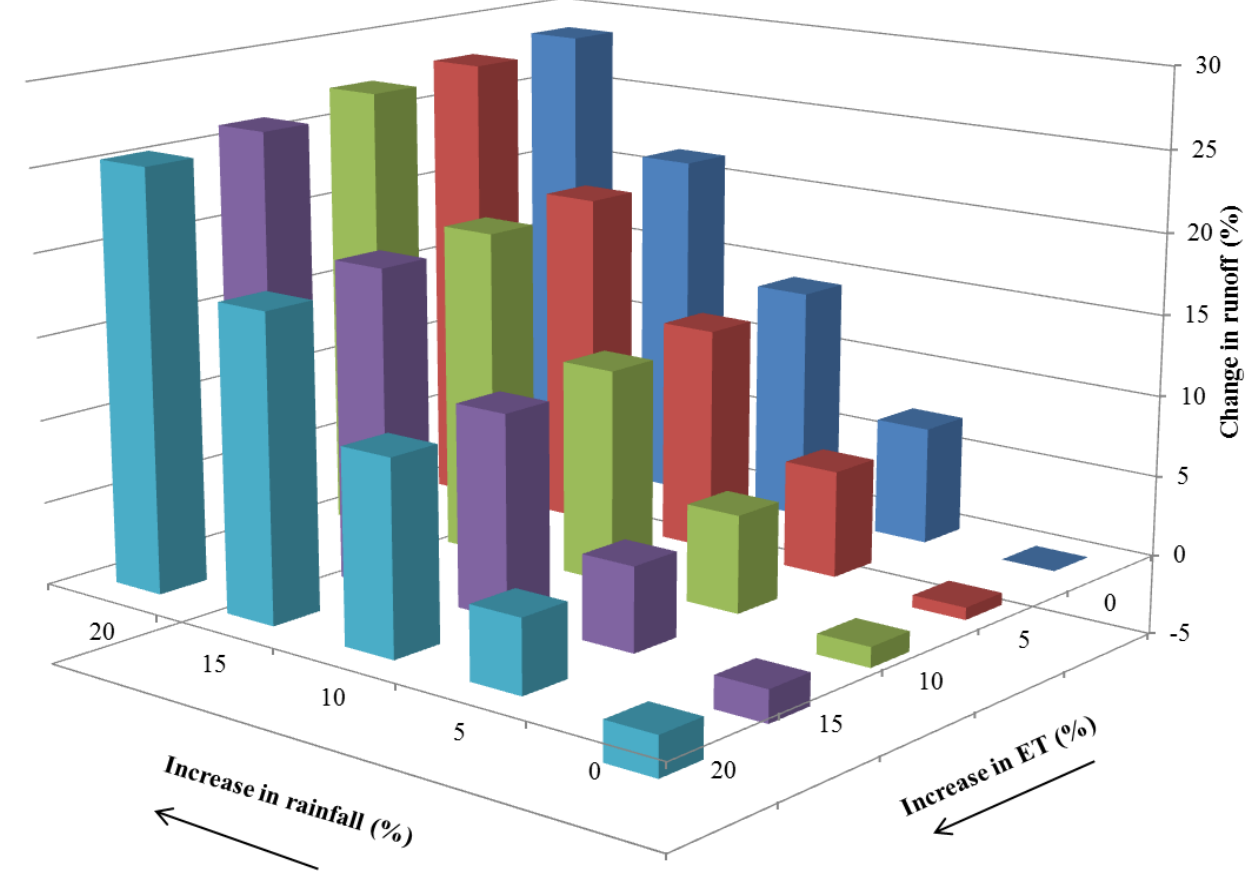

Figure 4.11: Changes in runoff for combined increase in rainfall and evapotranspiration 


\subsubsection{Combined Rainfall and Imperviousness Sensitivities:}

Increases in both rainfall and imperviousness simultaneously in the model showed different sensitivities than their linear summations, as well (Figure 4.12). An increase of $20 \%$ in rainfall only, produced $29 \%$ higher runoff than the base-line period. For imperviousness, a standalone $40 \%$ increase generated almost $26 \%$ more annual runoff. When, both the variables were altered together by 20 and $40 \%$ respectively, total annual runoff was increased by almost 60\%, which is much higher than their individual linear summations (55\%). Thus in order to design adequate stormwater management strategy for an area, the management should consider multiple scenarios at a time rather than considering only one scenario.

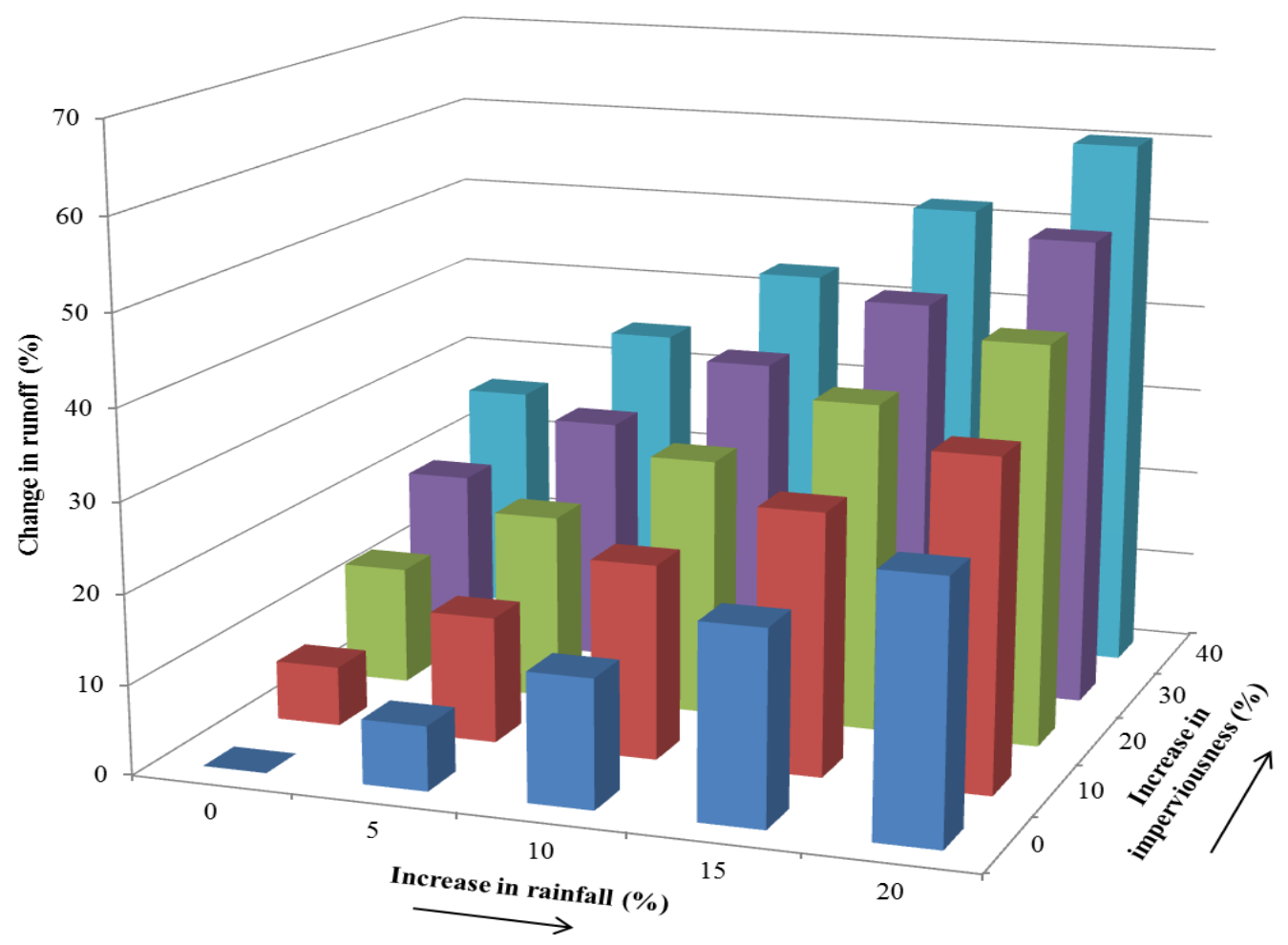

Figure 4.12: Changes in runoff for combined increase in rainfall and imperviousness 


\subsubsection{Combined Imperviousness and Evapotranspiration Sensitivities:}

The model was run by changing imperviousness and evapotranspiration variables simultaneously to quantify potential effects of urbanization and climate changes (i.e.; temperature) on runoff for the study area. Like combined rainfall and ET, simultaneous alteration of both imperviousness and ET produced less runoff than their linear summations (Figure 4.13). As increases in imperviousness, produced much higher runoffs, grater evaporation occurred from the surface due to increases in ET simultaneously, and thus the total runoff changes were slightly less than their arithmetic summations.

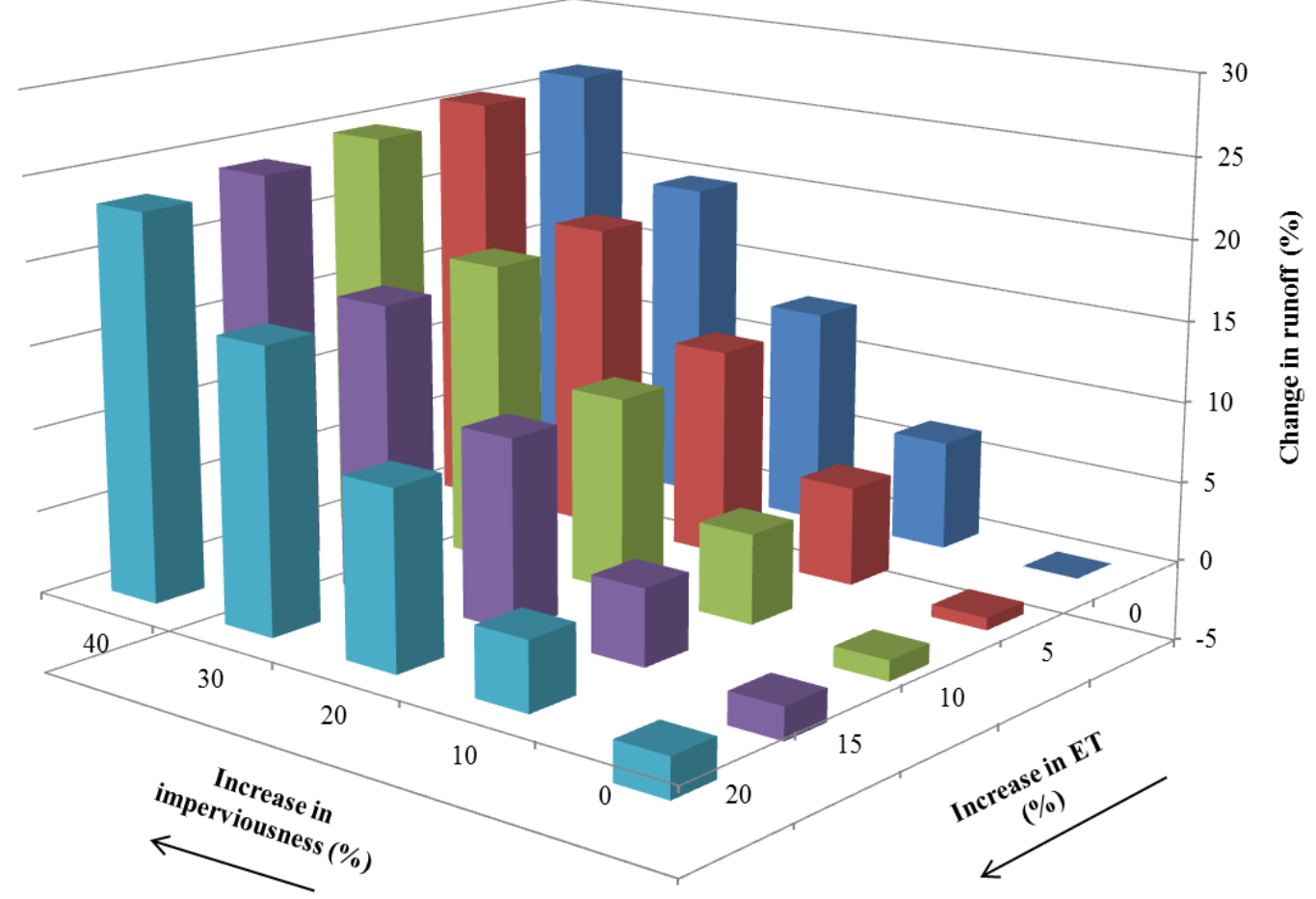

Figure 4.13: Changes in runoff for simultaneous increases in imperviousness and evapotranspiration 


\subsubsection{Comparison with Previous Studies:}

The study evaluated monthly and annual sensitivities of stormwater runoff to major hydro-climatic, land cover and hydrologic variables for Shingle Creek Basin in Central Florida. The developed model was calibrated by adjusting a wide range of parameters, mainly consisting of watershed characteristics, channel roughness, Green-Ampt coefficients and groundwater transfer functions. Among them, groundwater parameters, catchment width and channel roughness exhibited maximum sensitivities for the model. Different studies have calibrated SWMM model by considering different sets of parameters based on the study objectives and availability of the data. Abdul-Aziz and AlAmin (2014) considered different watershed and transport parameters, infiltration and groundwater parameters in calibrating a Stormwater Management Model for Miami River basin. Many studies (e.g., Jewell et al., 1978) focused on adjusting percent imperviousness values in calibrating Stormwater Management Model. In contrast, this study considered imperviousness values as a set parameter and adjusted different groundwater and watershed parameters for calibration purpose.

The study revealed rainfall and imperviousness as the most sensitive variables of stormwater runoff. The research findings are in compliance with the previous literature. Abdul-Aziz and Al-Amin (2014) also reported dominant influence of rainfall and imperviousness in stormwater generation for Miami River basin. The study found maximum monthly runoff sensitivities to rainfall in November and December, whereas runoff in wet months showed moderate to high sensitivities. In this current study, relative runoff changes in wet months were also moderate to high, while maximum runoff 
changes were observed for January and May. The discrepancy in monthly runoff sensitivities to rainfall may occur due to the differences in temporal distribution of rainfalls in these two study sites. Other studies (e.g., Chiew et al., 1995; Legesse et al., 2003) also identified significant changes in runoff due to changes in rainfall amounts.

Among the land cover and hydrologic variables, runoff showed maximum sensitivities to imperviousness. Previous literatures also found imperviousness as the most sensitive parameter of stormwater runoff among the hydrologic variables. Jewell et al. (1978) reported imperviousness as the most sensitive parameter of stormwater. AbdulAziz and Al-Amin (2014) also found runoff being significantly sensitive to imperviousness than other hydrologic variables.

In this study, evapotranspiration, basin slope and basin roughness exhibited less influence over runoff change for Shingle Creek Basin. Abdul-Aziz and Al-Amin (2014) also found slope as a less sensitive parameter of stormwater runoff in Miami River basin. The relative changes in runoff due to changes in basin roughness and evapotranspiration were higher in Miami River Basin. The discrepancy may occur due to the differences in land-use types between these two basins. Miami as a highly urbanized basin produced much larger runoff amount compared to Shingle Creek Basin. Thus, changing in ET and basin roughness exhibited relatively large changes in runoff amount in Miami compared to the current study site. 


\section{CHAPTER 5}

\section{CONCLUSIONS AND RECOMMENDATIONS}

\subsection{Conclusions}

We developed a dynamic rainfall runoff model for Shingle Creek Basin, in Central Florida using the EPA Storm Water Management Model (SWMM 5.1). The developed model incorporated all the important climatic and hydrologic processes (i.e., rainfall, evapotranspiration, groundwater as well as basin hydrologic characteristics) for runoff generation to quantify both monthly and annual stormwater sensitivities for the study basin. In general, stormwater models are built for small urban catchments and for singlestorm events, mainly due to the limited availability of appropriate data. In contrast, this study developed a Storm Water Management Model for a whole year and computed monthly and annual stormwater sensitivities to major hydro-climatic and hydrologic drivers.

The model was calibrated for 2012 with both daily and monthly mean stream flow near the outlet, considering a wide range of calibration parameters in order to ensure accurate model response for the whole study area. Overall, groundwater parameters (i.e., soil field capacity, groundwater transfer functions), along with basin characteristic width and channel roughness, exhibited maximum sensitivities for the model. Groundwater parameters showed relatively high sensitivities compared to other parameters as the study area is comprised of both natural and urban areas. Therefore, significant water exchange was observed among the transport and ground water compartment. The findings from this 
research can provide important insights for future studies in calibrating a stormwater model for similar urban-natural watersheds.

It is evident from the research that the climate, as well as different hydrologic and land cover variables, has profound impacts on runoff generation for a study area. Although the research findings might not be accurate enough for smaller subbasin scales, as the total water balance was preserved, the objective of evaluating stormwater responses to different drivers for the whole watershed area was well severed.

The study determined monthly and annual stormwater sensitivities to major climate, land cover and hydrologic variables. Runoff showed maximum sensitivity to rainfall compared to other variables. Notable monthly variations in stormwater were also observed for changing rainfall amounts in different scales. Overall, runoff in wet periods (i.e. May to October) showed moderate to high sensitives to rainfall, while dry months (i.e. November to March, except January) exhibited low to moderate sensitivities for Shingle Creek Basin. Runoff in January and May showed maximum sensitivities to rainfall for the study area. The rainfall depths along with the temporal variations controlled the stormwater sensitives to rainfall for the study area. For evapotranspiration, it showed relatively less influence on runoff compared to rainfall. Among the land cover and hydrologic variables, imperviousness showed greater influences on runoff generation than slope and basin roughness. The stormwater responses to combined hydro- climatic and land cover sensitivities were non-linear as the relative changes were different from the arithmetic summations of their individual contributions. The results can be useful for 
appropriate management of stormwater under changing climate, land use/cover and hydrology in different parts of the world.

\subsection{Recommendations}

The study evaluated monthly and annual sensitivities of stormwater runoff for Shingle Creek Basin, considering different hypothesized scenarios. Further studies can incorporate both regional climate model (RCM) projections as well as hypothesized scenarios in the model for assessing future runoff changes in the study area. Also, future research can compare stormwater sensitivities for similar watershed scales models in other regions to evaluate the robustness of the model predictions. 


\section{REFERENCES}

Abdul-Aziz, O. I., \& Al-Amin, S. (2014). Climate, land use and hydrologic sensitivities of stormwater quantity and quality in a complex coastal-urban watershed. Urban Water Journal, (ahead-of-print), 1-19.

Abdul-Aziz, O. I., Wilson, B. N., \& Gulliver, J. S. (2010). Two-zone model for stream and river ecosystems. Hydrobiologia, 638(1), 85-107.

Arnell, N. W., \& Reynard, N. S. (1996). The effects of climate change due to global warming on river flows in Great Britain. Journal of hydrology, 183(3), 397-424.

Beling, F. A., Garcia, J. I. B., Paiva, E. M. C. D., Bastos, G. A. P., \& Paiva, J. B. D. (2011, September). Analysis of the SWMM model parameters for runoff evaluation in periurban basins from southern Brazil. In 12nd international conference on urban drainage (pp. 11-16).

Berggren, K., Olofsson, M., Viklander, M., Svensson, G., \& Gustafsson, A. M. (2011). Hydraulic impacts on urban drainage systems due to changes in rainfall caused by climatic change. Journal of Hydrologic Engineering, 17(1), 92-98.

Bhaduri, B., Harbor, J., Engel, B., \& Grove, M. (2000). Assessing watershed-scale, longterm hydrologic impacts of land-use change using a GIS-NPS model. Environmental management, 26(6), 643-658.

Boorman, D. B., \& Sefton, C. E. M. (1997). Recognising the uncertainty in the quantification of the effects of climate change on hydrological response.Climatic Change, 35(4), 415-434.

Chang, H., \& Jung, I. W. (2010). Spatial and temporal changes in runoff caused by climate change in a complex large river basin in Oregon. Journal of Hydrology, 388(3), 186-207.

Chiew, F. H. S., Whetton, P. H., McMahon, T. A., \& Pittock, A. B. (1995). Simulation of the impacts of climate change on runoff and soil moisture in Australian catchments. Journal of hydrology, 167(1), 121-147.

Dolman, A. J. (2001). Soil-vegetation-atmosphere Transfer Schemes and Large-scale Hydrological Models: Proceedings of an International Symposium (Symposium S5)

Held During the Sixth Scientific Assembly of the International Association of Hydrological Sciences (IAHS) at Maastricht, The Netherlands, from 18 to 27 July 2001 (No. 270). International Assn of Hydrological Sciences.

Engeland, K., Gottschalk, L., \& Tallaksen, L. (2001). Estimation of regional parameters in a macro scale hydrological model. Nordic Hydrology, 32(3), 161-180. 
Ghosh, S., \& Dutta, S. (2012). Impact of climate change on flood characteristics in Brahmaputra basin using a macro-scale distributed hydrological model. Journal of earth system science, 121(3), 637-657.

Giron, Efrain, "Development of a SWMM-GIS Flood Model for New Orleans Drainage Pumping Station No 4 Basin" (2005). University of New Orleans Theses and Dissertations. Paper 261.

Gironás, J., Roesner, L. A., Crossman, L. A., \& Davis, J. (2010). A new applications manual for the Storm Water Management Model (SWMM). Environmental Modeling \& Software, 25(6), 813-814.

Graham, L. P. (2004). Climate change effects on river flow to the Baltic Sea.AMBIO: A Journal of the Human Environment, 33(4), 235-241.

Graham, L., \& Jacob, D. (2000). Using large-scale hydrologic modeling to review runoff generation processes in GCM climate models. Meteorologische Zeitschrift, 9(1), 4957.

Hay, L. E., Clark, M. P., Wilby, R. L., Gutowski Jr, W. J., Leavesley, G. H., Pan, Z. \& Takle, E. S. (2002). Use of regional climate model output for hydrologic simulations. Journal of Hydrometeorology, 3(5), 571-590.

He, J., Valeo, C., Chu, A., \& Neumann, N. F. (2011). Stormwater quantity and quality response to climate change using artificial neural networks. Hydrological Processes, 25(8), 1298-1312.

Hellström, C., \& Chen, D. (2003). Statistical downscaling based on dynamically downscaled predictors: application to monthly precipitation in Sweden.Advances in Atmospheric Sciences, 20(6), 951-958.

Houghton, J.T., Ding, Y., Griggs, D.J., Noguer, M., van der Linden, P.J., Dai, X., Maskell, K., Johnson, C. (2001). Climate Change 2001: The Scientific Basis, vol. 881. Cambridge University Press, Cambridge.

Jewell, T. K., \& Adrian, D. D. (1978). SWMM stormwater pollutant washoff functions. Journal of the Environmental Engineering Division, 104(5), 1036-1040.

Jiang, T., Chen, Y. D., Xu, C. Y., Chen, X., Chen, X., \& Singh, V. P. (2007). Comparison of hydrological impacts of climate change simulated by six hydrological models in the Dongjiang Basin, South China. Journal of hydrology, 336(3), 316-333.

Leavesley, G. H. (1994). Modeling the effects of climate change on water resources-a review. Climatic Change, 28(1-2), 159-177. 
Lee, J. G., \& Heaney, J. P. (2003). Estimation of urban imperviousness and its impacts on storm water systems. Journal of Water Resources Planning and Management, 129(5), 419-426.

Legesse, D., Vallet-Coulomb, C., \& Gasse, F. (2003). Hydrological response of a catchment to climate and land use changes in Tropical Africa: case study South Central Ethiopia. Journal of Hydrology, 275(1), 67-85.

Loaiciga, H. A., Valdes, J. B., Vogel, R., Garvey, J., \& Schwarz, H. (1996). Global warming and the hydrologic cycle. Journal of Hydrology, 174(1), 83-127.

Ma, X., Fukushima, Y., Hiyama, T., Hashimoto, T., \& Ohata, T. (2000). A macro-scale hydrological analysis of the Lena River basin. Hydrological Processes, 14(3), 639651.

Matheussen, B., Kirschbaum, R. L., Goodman, I. A., O'Donnell, G. M., \& Lettenmaier, D. P. (2000). Effects of land cover change on streamflow in the interior Columbia River Basin (USA and Canada). Hydrological Processes, 14(5), 867-885.

Nash, J., \& Sutcliffe, J. V. (1970). River flow forecasting through conceptual models part I-A discussion of principles. Journal of hydrology, 10(3), 282-290.

National Land Cover Database 2011 Website, 2015, http://www.mrlc.gov/nlcd2011.php

Němec, J., \& Schaake, J. (1982). Sensitivity of water resource systems to climate variation. Hydrological Sciences Journal, 27(3), 327-343.

Nijssen, B., O'Donnell, G. M., Hamlet, A. F., \& Lettenmaier, D. P. (2001). Hydrologic sensitivity of global rivers to climate change. Climatic change, 50(1-2), 143-175.

Obeysekera, J., Park, J., Irizarry-Ortiz, M., Trimble, P., Barnes, J., Van Arman, J., Said, W., \& Gadzinski, E. (2011). Past and projected trends in climate and sea level for South Florida. Interdepartmental Climate Change Group. South Florida Water Management District, West Palm Beach, Florida, Hydrologic and Environmental Systems Modeling Technical Report.

Rossman, L. A. (2010). Storm water management model user's manual, version 5.0. National Risk Management Research Laboratory, Office of Research and Development, US Environmental Protection Agency, Cincinnati, OH.

Samuelsson, P., Bringfelt, B., \& Graham, L. P. (2003). The role of aerodynamic roughness for runoff and snow evaporation in land-surface schemes-comparison of uncoupled and coupled simulations. Global and Planetary Change, 38(1), 93-99. 
South Florida Water Management District Website, 2015, http://www.sfwmd.gov/nexrad2/\#TextBasedSearch

US Geological Survey (USGS), 2013. Hydrologic Unit Maps, Available from http://water.usgs.gov/GIS/huc.html

USGS Florida Water Science Center Website, 2015, http://fl.water.usgs.gov/et/

USGS Water Data for the Nation Website, 2015, http://waterdata.usgs.gov/nwis/

Vastila, K., Kummu, M., Sangmanee, C., \& Chinvanno, S. (2010). Modelling climate change impacts on the flood pulse in the Lower Mekong floodplains.Journal of Water and Climate Change Vol, 1(1), 67-86.

Wetterhall, F., Halldin, S., \& Xu, C. Y. (2005). Statistical precipitation downscaling in central Sweden with the analogue method. Journal of Hydrology, 306(1), 174-190.

Wetterhall, F., Halldin, S., \& Xu, C. Y. (2007). Seasonality properties of four statisticaldownscaling methods in central Sweden. Theoretical and Applied Climatology, 87(14), 123-137.

Wilby, R. L., Hay, L. E., Gutowski, W. J., Arritt, R. W., Takle, E. S., Pan, Z., \& Clark, M. P. (2000). Hydrological responses to dynamically and statistically downscaled climate model output. Geophysical Research Letters, 27(8), 1199-1202.

Xu, C. Y. (1999). From GCMs to river flow: a review of downscaling methods and hydrologic modelling approaches. Progress in Physical Geography, 23(2), 229-249.

$\mathrm{Xu}, \mathrm{C}$. Y. (2000). Modelling the effects of climate change on water resources in central Sweden. Water Resources Management, 14(3), 177-189.

Xu, C. Y., Widén, E., \& Halldin, S. (2005). Modelling hydrological consequences of climate change-progress and challenges. Advances in Atmospheric Sciences, 22(6), 789-797.

Yu, H., Huang, G., \& Wu, C. (2014). Application of the stormwater management model to a piedmont city: a case study of Jinan City, China. Water Science \& Technology, 70(5), 858-864. 


\section{APPENDICES}

Appendix 1. Relative sensitivity coefficients (dimensionless) of monthly and annual runoffs for different increases in rainfalls.

\begin{tabular}{ccccc}
\hline & \multicolumn{4}{c}{ Increase in rainfall (\%) } \\
\cline { 2 - 5 } Time & $5 \%$ & $10 \%$ & $15 \%$ & $20 \%$ \\
\hline Jan & 1.563 & 1.548 & 1.550 & 1.551 \\
Feb & 1.210 & 1.142 & 1.079 & 1.160 \\
Mar & 1.088 & 1.210 & 1.238 & 1.276 \\
Apr & 1.231 & 1.162 & 1.187 & 1.201 \\
May & 1.493 & 1.495 & 1.503 & 1.550 \\
Jun & 1.490 & 1.430 & 1.407 & 1.425 \\
Jul & 1.311 & 1.516 & 1.567 & 1.497 \\
Aug & 1.489 & 1.459 & 1.486 & 1.465 \\
Sep & 1.398 & 1.441 & 1.444 & 1.455 \\
Oct & 1.496 & 1.536 & 1.503 & 1.452 \\
Nov & 1.239 & 1.237 & 1.232 & 1.240 \\
Dec & 1.391 & 1.220 & 1.275 & 1.210 \\
Annual & 1.438 & 1.431 & 1.433 & 1.430 \\
\hline
\end{tabular}


Appendix 2. Relative sensitivity coefficients (dimensionless) of monthly and annual runoffs for different increases in imperviousness.

\begin{tabular}{ccccc}
\hline & \multicolumn{4}{c}{ Increase in imperviousness (\%) } \\
\cline { 2 - 5 } Time & $10 \%$ & $20 \%$ & $30 \%$ & $40 \%$ \\
\hline Jan & 0.851 & 0.853 & 0.843 & 0.838 \\
Feb & 1.022 & 0.988 & 0.990 & 0.984 \\
Mar & 0.934 & 0.926 & 0.914 & 0.910 \\
Apr & 1.006 & 0.963 & 0.971 & 0.959 \\
May & 0.861 & 0.855 & 0.850 & 0.850 \\
Jun & 0.560 & 0.538 & 0.538 & 0.529 \\
Jul & 0.683 & 0.660 & 0.676 & 0.690 \\
Aug & 0.622 & 0.623 & 0.631 & 0.624 \\
Sep & 0.722 & 0.745 & 0.748 & 0.731 \\
Oct & 0.613 & 0.672 & 0.635 & 0.614 \\
Nov & 0.933 & 0.947 & 0.930 & 0.923 \\
Dec & 0.891 & 0.904 & 0.918 & 0.918 \\
Annual & 0.665 & 0.661 & 0.662 & 0.655 \\
\hline
\end{tabular}


Appendix 3. Relative sensitivity coefficients (dimensionless) of monthly and annual runoffs for different increases in ET.

\begin{tabular}{ccccc}
\hline & \multicolumn{4}{c}{ Increase in ET (\%) } \\
\cline { 2 - 5 } Time & $5 \%$ & $10 \%$ & $15 \%$ & $20 \%$ \\
\hline Jan & -0.204 & -0.198 & -0.184 & -0.172 \\
Feb & -0.097 & -0.018 & -0.053 & -0.020 \\
Mar & -0.096 & -0.107 & -0.146 & -0.147 \\
Apr & -0.075 & -0.091 & -0.066 & -0.074 \\
May & -0.163 & -0.161 & -0.161 & -0.162 \\
Jun & -0.236 & -0.153 & -0.162 & -0.140 \\
Jul & -0.102 & -0.131 & -0.133 & -0.095 \\
Aug & -0.145 & -0.112 & -0.126 & -0.119 \\
Sep & 0.010 & -0.137 & -0.096 & -0.119 \\
Oct & -0.144 & -0.029 & -0.108 & -0.121 \\
Nov & -0.093 & -0.088 & -0.076 & -0.077 \\
Dec & -0.114 & -0.101 & -0.101 & -0.058 \\
Annual & -0.149 & -0.124 & -0.132 & -0.121 \\
\hline & & & &
\end{tabular}


Appendix 4. Relative sensitivity coefficients (dimensionless) of monthly and annual runoffs for $20 \%$ increases in roughness and slope.

\begin{tabular}{ccc}
\hline Time & Roughness & Slope \\
\hline Jan & -0.144 & 0.070 \\
Feb & -0.002 & 0.034 \\
Mar & -0.044 & 0.016 \\
Apr & -0.012 & 0.036 \\
May & -0.059 & 0.025 \\
Jun & -0.020 & 0.013 \\
Jul & -0.026 & 0.051 \\
Aug & -0.031 & 0.021 \\
Sep & -0.011 & 0.013 \\
Oct & -0.036 & 0.059 \\
Nov & -0.070 & 0.045 \\
Dec & -0.034 & 0.014 \\
Annual & -0.026 & 0.024 \\
\hline
\end{tabular}


Appendix 5. Combined rainfall and evapotranspiration sensitivities of potential annual storm runoffs in the Shingle Creek Basin

\begin{tabular}{|c|c|c|c|c|c|c|}
\hline \multirow[b]{2}{*}{ Parameter } & & \multicolumn{5}{|c|}{ Increase in rainfall (\%) } \\
\hline & & 0 & 5 & 10 & 15 & 20 \\
\hline \multirow[t]{5}{*}{ Increase in ET (\%) } & 0 & 0 & 7.19 & 14.31 & 21.50 & 28.60 \\
\hline & 5 & -0.75 & 6.47 & 13.59 & 20.46 & 27.88 \\
\hline & 10 & -1.24 & 5.88 & 12.91 & 19.84 & 27.29 \\
\hline & 15 & -1.98 & 5.07 & 12.21 & 19.29 & 26.20 \\
\hline & 20 & -2.43 & 4.43 & 11.63 & 18.41 & 25.44 \\
\hline
\end{tabular}

Appendix 6. Combined rainfall and imperviousness sensitivities of potential annual storm runoffs in the Shingle Creek Basin

\begin{tabular}{|c|c|c|c|c|c|c|}
\hline \multirow[b]{2}{*}{ Parameter } & & \multicolumn{5}{|c|}{ Increase in rainfall (\%) } \\
\hline & & 0 & 5 & 10 & 15 & 20 \\
\hline \multirow{5}{*}{$\begin{array}{l}\text { Increase in } \\
\text { imperviousness (\%) }\end{array}$} & 0 & 0 & 7.19 & 14.31 & 21.50 & 28.60 \\
\hline & 10 & 6.65 & 14.07 & 21.67 & 29.06 & 36.53 \\
\hline & 20 & 13.23 & 20.89 & 28.88 & 36.68 & 44.56 \\
\hline & 30 & 19.86 & 27.72 & 36.04 & 44.21 & 52.44 \\
\hline & 40 & 26.18 & 34.57 & 42.99 & 51.87 & 60.33 \\
\hline
\end{tabular}


Appendix 7. Combined imperviousness and evapotranspiration sensitivities of potential annual storm runoffs in the Shingle Creek Basin

\begin{tabular}{|c|c|c|c|c|c|c|}
\hline \multirow[b]{2}{*}{ Parameter } & & \multicolumn{5}{|c|}{ Increase in imperviousness (\%) } \\
\hline & & 0 & 10 & 20 & 30 & 40 \\
\hline \multirow[t]{5}{*}{ Increase in ET (\%) } & 0 & 0 & 6.65 & 13.23 & 19.86 & 26.18 \\
\hline & 5 & -0.75 & 5.93 & 12.64 & 18.81 & 25.60 \\
\hline & 10 & -1.24 & 5.38 & 11.68 & 18.21 & 24.79 \\
\hline & 15 & -1.98 & 4.59 & 11.40 & 17.57 & 23.99 \\
\hline & 20 & -2.43 & 4.16 & 10.68 & 17.06 & 23.32 \\
\hline
\end{tabular}

